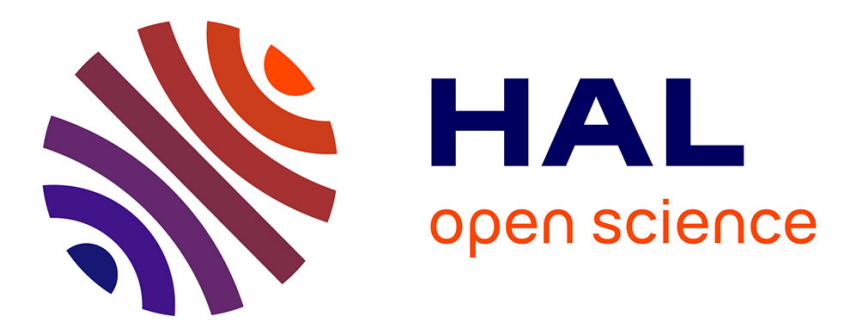

\title{
CoMFA and CoMSIA analyses on 1,2,3,4-tetrahydropyrrolo[3,4-]indole and benzimidazole derivatives as selective CB2 receptor agonists
}

Elena Cichero, Sara Cesarini, Luisa Mosti, Paola Fossa

\section{- To cite this version:}

Elena Cichero, Sara Cesarini, Luisa Mosti, Paola Fossa. CoMFA and CoMSIA analyses on 1,2,3,4tetrahydropyrrolo[3,4-]indole and benzimidazole derivatives as selective CB2 receptor agonists. Journal of Molecular Modeling, 2010, 16 (9), pp.1481-1498. 10.1007/s00894-010-0664-1 . hal-00568342

\section{HAL Id: hal-00568342 \\ https://hal.science/hal-00568342}

Submitted on 23 Feb 2011

HAL is a multi-disciplinary open access archive for the deposit and dissemination of scientific research documents, whether they are published or not. The documents may come from teaching and research institutions in France or abroad, or from public or private research centers.
L'archive ouverte pluridisciplinaire HAL, est destinée au dépôt et à la diffusion de documents scientifiques de niveau recherche, publiés ou non, émanant des établissements d'enseignement et de recherche français ou étrangers, des laboratoires publics ou privés. 


\section{Editorial Manager(tm) for Journal of Molecular Modeling Manuscript Draft}

Manuscript Number: JMM0925R1

Title: CoMFA and CoMSIA analyses on 1,2,3,4-tetrahydropyrrolo[3,4-b]indole and benzimidazole derivatives as selective $\mathrm{CB} 2$ receptor agonists

Article Type: Original paper

Keywords: cannabinoid receptor; CB2 agonist; 3D-QSAR; CoMFA; CoMSIA

Corresponding Author: Dr. Elena Cichero,

Corresponding Author's Institution:

First Author: Elena Cichero

Order of Authors: Elena Cichero; Sara Cesarini; Luisa Mosti; Paola Fossa

Abstract: Novel classes of cannabinoid 2 receptor (CB2) agonists based on 1,2,3,4-

tetrahydropyrrolo[3,4-b]indole and benzimidazole scaffolds have shown high binding affinity toward CB2 receptor and good selectivity over cannabinoid 1 receptor (CB1). A computational study of Comparative Molecular Fields Analysis (CoMFA) and Comparative Molecular Similarity Indices Analysis (CoMSIA) was performed, initially on each series of agonists, and subsequently on all compounds together, in order to identify the key structural features impacting their binding affinity. The final CoMSIA model resulted to be the more predictive, showing cross-validated r2 (rcv2) $=0.680$, non cross-validated $\mathrm{r} 2(\mathrm{rncv} 2)=0.97$ and test set $\mathrm{r} 2(\mathrm{r} 2 \mathrm{pred})=0.93$. The study provides useful suggestions for the design of new analogues with improved affinity.

Response to Reviewers: In this manuscript, CoMFA and CoMSIA analyses were performed as suggested by reviewer\#1. Thus, to derive the final CoMFA and CoMSIA models, 44 compounds were assigned to the training set, for model generation, and 19 ligands to the test set, for model validation. The test set molecules represent the $30 \%$ of the training set and cover $4 \log$ orders of magnitude. 


\section{Abstract graphic}

Click here to download Abstract graphic: Graphical_Abstract.doc

Graphical Abstract

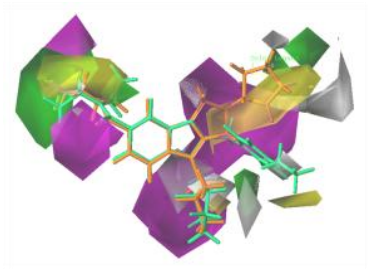




\title{
CoMFA and CoMSIA analyses on 1,2,3,4-tetrahydropyrrolo[3,4- $b$ ]indole and benzimidazole derivatives as selective $\mathrm{CB} 2$ receptor agonists
}

Received: 21.07.2009 / Accepted: 21.01.2010

Elena Cichero ${ }^{\bowtie}$, Sara Cesarini, Luisa Mosti and Paola Fossa

Dipartimento di Scienze Farmaceutiche. Università degli Studi di Genova. Viale Benedetto XV n.3. 16132 - Genova. Italy

${ }^{\circledR}$ Tel: +39-010-3538361; Fax: +39-010-3538358; Email:cichero@unige.it

\begin{abstract}
Novel classes of cannabinoid 2 receptor (CB2) agonists based on 1,2,3,4tetrahydropyrrolo[3,4- $b]$ indole and benzimidazole scaffolds have shown high binding affinity toward CB2 receptor and good selectivity over cannabinoid 1 receptor (CB1). A computational study of Comparative Molecular Fields Analysis (CoMFA) and Comparative Molecular Similarity Indices Analysis (CoMSIA) was performed, initially on each series of agonists, and subsequently on all compounds together, in order to identify the key structural features impacting their binding affinity. The final CoMSIA model resulted to be the more predictive, showing cross-validated $\mathrm{r}^{2}\left(\mathrm{r}_{\mathrm{cv}}{ }^{2}\right)=0.680$, non cross-validated $\mathrm{r}^{2}\left(\mathrm{r}_{\mathrm{ncv}}{ }^{2}\right)=0.97$ and test set $r^{2}\left(r^{2}\right.$ pred $)=0.93$. The study provides useful suggestions for the design of new analogues with improved affinity.
\end{abstract}

Keywords Cannabinoid receptor $\cdot \mathrm{CB} 2$ agonist $\cdot 3 \mathrm{D}-\mathrm{QSAR} \cdot \mathrm{CoMFA} \cdot \mathrm{CoMSIA}$ 


\section{Introduction}

Cannabinoid receptors interact with cannabinoid drugs including the classical cannabinoids, such as $\Delta^{9}$ - tetrahydrocannabinol $\left(\Delta^{9}\right.$-THC), their synthetic analogs and the endogenous cannabinoids [1-4]. The pharmacological effects of cannabinoids are mediated throught at least two receptors, the cannabinoid 1 receptor (CB1) and the cannabinoid 2 receptor $(\mathrm{CB} 2)$, even if at present there is some experimental evidence that supports the existence of additional types of cannabinoid receptors [5-7]. While CB1 is located principally in the central nervous system, CB2 is found in peripheral tissues, such as the spleen, tonsils and thymus. This subtype is of particular interest, since it has been identified as a potential target for therapeutic immune treatment, due to its involvement in signal transduction processes in the immune system. Furthermore, CB2 selective compounds were active in different neuropathic and inflammatory pain models [8-12]. Some neuroprotective roles have also been associated with CB2 agents, that could lead to the prevention of some neurodegenerative disorders, such as Huntington and Alzheimer's diseases [13-15]. Other studies have also highlighted potentials roles for CB2 in cancer [16, 17], multiple sclerosis [18] and bone regeneration $[19,20]$. Since majority of CB2 receptors are distributed in peripheral tissues, with only low levels in neurons of central nervous system, centrally mediated side-effects would be greatly diminished with CB2 selective agents.

Both CB1 and CB2 belong to the large family of G-protein coupled receptors (GPCRs) [21] controlling a wide variety of signal transduction. Since GPCR are membrane proteins, their expression, purification, crystallization and structure determination present major challenges to the discovery of new drugs. In the absence of experimental data about human cannabinoid receptor 3D structures, computer-aided GPCR-targeted drug design can be performed on the basis of ligand-based modeling techniques, such as pharmacophore model generation or 3DQSAR analysis.

Recently, novel classes of CB2 agonists based on 1,2,3,4-tetrahydropyrrolo[3,4- $b$ ]indole and benzimidazole scaffolds [22, 23] (in Fig. 1, representative compounds $\mathbf{8}$ and $\mathbf{3 1}$ are depicted) have shown high binding affinity toward CB2 receptor and good selectivity over CB1 receptor. 
In order to identify the key structural features impacting the binding affinity, and with the aim at providing useful suggestions for the synthesis of new selective analogues with improved affinity, a computational study of Comparative Molecular Fields Analysis (CoMFA) and Comparative Molecular Similarity Indices Analysis (CoMSIA) was performed. Initially, the two classes of selective CB2 agonists were studied separately: CoMFA and CoMSIA analyses were performed on both 1,2,3,4-tetrahydropyrrolo[3,4-b]indole derivatives and benzimidazole compounds, and one model for each series was derived (models A and B, respectively). Subsequently, all compounds together (in the same minimized conformation used for the generation of models A and B) were aligned on the basis of the common 1,5-disubstitutedindole or 1,5-disubstituted-benzimidazole scaffold (common scaffold depicted in blue in Fig. 1), and the final CoMFA and CoMSIA model $\mathrm{C}$ was calculated. The superimposition of the two series of agonists was allowed not only by the common structural features of the two scaffolds, but also by the spatial correspondence of the molecular field maps previously elaborated for each series (models A and B). The generation of a single model (model C) for the two series of compounds offers the possibility to obtain additional information and suggestions for the design of new potent and selective analogues.

\section{Materials and methods}

\section{Data set}

A dataset of twenty-seven 1,2,3,4-tetrahydropyrrolo[3,4-b]indole derivatives (Table 1, compounds 1-27) and thirty-six benzimidazole derivatives (Table 2, compounds 28-63), screened according to the same pharmacological protocol, were selected from literature [22, 23]. All the compounds have been built, parameterized (Gasteiger-Hückel method) and energy minimized within MOE using MMFF94 forcefield [24]. 


\section{D-QSAR analysis}

In the absence of crystallographic data about human CB2 3D structure, the ligand-based approach of CoMFA and CoMSIA analyses [25-26], performed using Sybyl7.0 software [27], could provide a complementary tool for drug design.

Initially, the two classes of selective CB2 agonists were studied separately: CoMFA and CoMSIA analyses were performed on compounds 1-27 (aligned on the common 1,2,3,4tetrahydropyrrolo[3,4-b]indole moiety) and on compounds 28-63 (aligned on the benzimidazole moiety), and one model for each series was derived (models A and B, respectively). Subsequently, all compounds together were aligned on the basis of the common 1,5-disubstituted-indole or 1,5-disubstitued-benzimidazole scaffold (rigid alignment of the same minimized conformations used to build models $\mathrm{A}$ and $\mathrm{B}$ ) and the final CoMFA and CoMSIA model $\mathrm{C}$ was calculated.

\section{Training set and test set}

\section{1,2,3,4-Tetrahydropyrrolo[3,4-b]indole derivatives (Model A)}

All the compounds were grouped into a training set, for model generation, and a test set, for model validation, containing 19 and 8 compounds respectively. Both the training and the test set were divided manually according to a representative range of biological activities and structural variations. For QSAR analysis, Ki values have been transformed into pKi values and then used as response variables. Compound binding affinity covered 3 log orders of magnitude.

\section{Benzimidazole derivatives (Model B)}

All the compounds were grouped into a training set, for model generation, and a test set, for model validation, containing 25 and 11 compounds respectively. Both the training and the test set were divided manually according to a representative range of biological activities and structural variations. For QSAR analysis, Ki values have been transformed into pKi values and then used as response variables. Compound binding affinity covered 4 log orders of magnitude. 


\section{1,2,3,4-Tetrahydropyrrolo[3,4-b]indole and Benzimidazole derivatives (Model C)}

To derive the final CoMFA and CoMSIA models, 44 compounds were assigned to the training set, for model generation, and 19 ligands to the test set, for model validation. The test set molecules, which are the same ligands belonging to the test sets of the previously described statistical studies, represent the $30 \%$ (considered an appropriate percentage to validate a molecular model) of the training set. For QSAR analysis, Ki values have been transformed into pKi values and then used as response variables. Compound binding affinity covered $4 \log$ orders of magnitude.

\section{CoMFA and CoMSIA interaction energies}

CoMFA method [23] is a widely used 3D-QSAR technique to relate the biological activity of a series of molecules to their steric and electrostatic fields, which are calculated placing the aligned molecules, one by one, into a 3D cubic lattice with a $2 \AA$ grid spacing. The van der Waals potential and Coulombic terms, which represent steric and electrostatic fields, respectively, were calculated using the standard Tripos force field method. The columnfiltering threshold value was set to $2.0 \mathrm{kcal} \mathrm{mol}^{-1}$ to improve the signal-noise ratio. A methyl probe with a +1 charge was used to calculate the CoMFA steric and electrostatic fields. A 30 $\mathrm{kcal} \mathrm{mol}^{-1}$ energy cut-off was applied to avoid infinity of energy values inside the molecule. The CoMSIA method [24] calculates five descriptors, namely steric, electrostatic and hydrophobic parameters, and the H-bond donor and H-bond acceptor properties. The similarity index descriptors were calculated using the same lattice box employed for the CoMFA calculations and a $\mathrm{sp}^{3}$ carbon as probe atom with a +1 charge, +1 hydrophobicity and $+1 \mathrm{H}$-bond donor and $+1 \mathrm{H}$-bond acceptor properties.

\section{Partial least square (PLS) analysis and models validation}

The partial least-squares (PLS) approach, an extension of the multiple regression analysis, was used to derive the 3D-QSAR models. CoMFA and CoMSIA descriptors were used as independent variables and $\mathrm{pEC}_{50}$ values were used as dependent variables. Prior to the PLS analysis, CoMFA and CoMSIA columns with a variance of less than $2.0 \mathrm{kcal} \mathrm{mol}^{-1}$ were filtered by using column filtering to improve the signal-to-noise ratio. 
The leave one out (LOO) cross-validation method was used to check the predictivity of the derived model and to identify the optimal number of components (ONC) leading to the highest cross-validated $\mathrm{r}^{2}\left(r_{c v}^{2}\right)$. In the LOO methodology, one molecule is omitted from the dataset and a model is derived involving the rest of the compounds. Employing this model, the activity of the omitted molecule is then predicted.

The ONC obtained from cross-validation methodology was used in the subsequent regression model. Final CoMFA and CoMSIA models were generated using non-cross-validated PLS analysis. To further assess the statistical confidence and robustness of the derived models, a 100-cycle bootstrap analysis was performed. This is a procedure in which $n$ random selections out of the original set of $n$ objects are performed several times (100-times were required to obtain a good statistical information). In each run, some objects may not be included in the PLS analysis, whereas some others might be included more than once. The mean correlation coefficient is represented as bootstrap $r^{2}\left(\mathrm{r}^{2}\right.$ boot $)$.

\section{Predictive correlation coefficient $\left(\mathbf{r}^{2}\right.$ pred $)$}

To further validate the CoMFA and CoMSIA derived model, the predictive ability for the test set of compounds (expressed as $\mathrm{r}^{2}$ pred) was determined by using the following equation:

$$
\mathrm{r}_{\text {pred }}^{2}=(\mathrm{SD}-\mathrm{PRESS}) / \mathrm{SD}
$$

$\mathrm{SD}$ is the sum of the squared deviations between the biological activities of the test set molecules and the mean activity of the training set compounds and PRESS is the sum of the squared deviation between the observed and the predicted activities of the test set compounds.

All calculations were carried out using a PC running the Windows XP operating system and an SGI O2 Silicon Graphics. 


\section{Results and discussion}

\section{CoMFA and CoMSIA analyses}

Model A

To develop the 3D-QSAR analyses, 1-27 (Table 1) were manually aligned on the basis of the tetrahydropyrrolo[3,4- $b]$ indole common moiety.

CoMFA analysis was performed dividing compounds 1-27 into a training set (1-3, 5-12, 16, 18-20, 22, 24, 25, 27) for model generation and into a test set $(4,13-15,17,21,23,26)$ for model validation. CoMFA and CoMSIA studies were developed using, respectively, CoMFA steric and electrostatic fields and CoMSIA steric, electrostatic, hydrophobic, H-bond donor and $\mathrm{H}$-bond acceptor properties, as independent variables, and the ligand $\mathrm{pKi}$ as dependent variable.

The final CoMFA model was generated employing non-cross-validated PLS analysis with the optimum number of components $(\mathrm{ONC}=3)$ to give a non-cross validated $\mathrm{r}^{2}\left(\mathrm{r}^{2}{ }_{\text {ncv }}\right)=0.942$, Standard Error of Estimate $(\mathrm{SEE})=0.254$, steric contribution $=0.432$ and electrostatic contribution $=0.568$. The model reliability thus generated was supported by bootstrapping results. All statistical parameters supporting CoMFA model are reported in Table 3.

A CoMSIA model consisting of steric, electrostatic, hydrophobic, $\mathrm{H}$-bond donor and $\mathrm{H}$-bond acceptor fields with $\mathrm{a}^{2}{ }_{\mathrm{ncv}}=0.970, \mathrm{SEE}=0.232$, steric contribution $=0.176$, electrostatic contribution $=0.253$, hydrophobic contribution $=0.232$, H-bond acceptor contribution $=$ 0.194 and H-bond donor contribution $=0.144$ was derived. All statistical parameters supporting CoMSIA model are reported in Table 4.

Experimental and predicted binding affinities values for the training set and test set are reported in Table 5.

As shown in Fig. 2a (for simplicity, only the structure of compound 8, displaying the highest $\mathrm{pKi}$ value in the tetrahydropyrrolo[3,4- $b$ ]indole series, is depicted as representative), the steric contour map predicts favorable interaction polyhedra (green) around the position 4 of piperidine in substituent R1 and around group R, and unfavorable polyhedra (yellow) in 
proximity of the positions 3 of the cyclopentyl ring in substituent R2. The reliability of the steric map calculations is verified by the higher affinity of $7(\mathrm{pKi}=8.15)$ compared to that of $\mathbf{1 1}(\mathrm{pKi}=7.76)$ and $\mathbf{1 2}(\mathrm{pKi}=7.35)$, and by the following affinity trends: $\mathbf{8}(\mathrm{pKi}=8.38)>\mathbf{7}$ $(\mathrm{pKi}=8.15)>\mathbf{6}(\mathrm{pKi}=8.10)$, and $24(\mathrm{pKi}=8.20) \approx 7(\mathrm{pKi}=8.15)>\mathbf{2 5}(\mathrm{pKi}=6.03)>\mathbf{2 6}$ $(\mathrm{pKi}=5.70)$.

According to the electrostatic field contour map of the CoMFA analysis plotted in Fig. 2b, less positive moieties are predicted to be favored (red areas) in proximity of one oxygen of the $\mathrm{R}$ sulfonyl group, near one of the two positions 3 of R1 piperidine, and around position 2 and between positions 4 and 5 of R2 cyclopentyl. On the other hand, more electropositive substituents are predicted to be beneficial (blue area) around position 3 of the cyclopentyl. These results are in agreement with the $\mathrm{pKi}$ value trend $19(\mathrm{pKi}=7.75)>17(\mathrm{pKi}=7.56)>$ $18(\mathrm{pKi}=6.67)$, and with the higher affinity of 6-9 $(\mathrm{pKi}=8.03-8.38)$ in comparison with that of 3-5 $(\mathrm{pKi}=6.97-7.63)$.

The CoMSIA steric and electrostatic regions are in agreement with the CoMFA steric and electrostatic areas.

The calculated CoMSIA hydrophobic contours (Fig. 3) display favorable hydrophobic substituents (yellow polyhedra) in proximity of the position 4 of R1 piperidine and around the positions 3 of R2 cyclopentyl; at a higher distance from the cyclopentyl, hydrophobic substituents become disfavored (white areas). The reliability of the hydrophobic map calculation is verified by the following affinity trends: $\mathbf{7}(\mathrm{pKi}=8.15)>\mathbf{1 4}(\mathrm{pKi}=7.56)>\mathbf{1 3}$ $(\mathrm{pKi}=6.51)$, and $24(\mathrm{pKi}=8.20) \approx 7(\mathrm{pKi}=8.15)>25(\mathrm{pKi}=6.03)>26(\mathrm{pKi}=5.70)$.

Fig. 4a illustrates that H-bond acceptor groups are predicted to be beneficial (magenta areas) in proximity of the oxygen atoms of R sulfonyl group, and detrimental (green polyhedra) near the position 4 of R2 cyclopentyl and in the region surrounding the position 4 of R1 piperidine. Moreover, H-bond donor functions (Fig. 4b) would result to be unfavorable (cyan polyhedra) around the sulfonyl group. Accordingly, compounds 6-9 $(\mathrm{pKi}=8.03-8.38)$ show higher $\mathrm{pKi}$ values than 3-5 $(\mathrm{pKi}=6.97-7.63)$, and $7(\mathrm{pKi}=8.15)$ and $\mathbf{1 1}(\mathrm{pKi}=7.76)$ display higher binding affinity than $\mathbf{1 2 - 1 4}(\mathrm{pKi}=6.51-7.56)$. Besides, the $\mathrm{pKi}$ values of $7(\mathrm{pKi}=8.15)$ and 3 $(\mathrm{pKi}=7.07)$ are higher than those of $\mathbf{1 7}(\mathrm{pKi}=7.56)$ and $\mathbf{2}(\mathrm{pKi}=5.33)$, respectively. 


\section{Model B}

Compounds 28-63 (Table 2) were manually aligned on the basis of the benzimidazole common moiety. CoMFA analysis was performed dividing compounds $\mathbf{2 8 - 6 3}$ into a training set $(28,29,31,32,34-42,45,48-52,55,58-61,63)$ for model generation and into a test set $(30,33,43,44,46,47,53,54,56,57,62)$ for model validation. CoMFA and CoMSIA studies were developed using, respectively, CoMFA steric and electrostatic fields and CoMSIA steric, electrostatic, hydrophobic, H-bond donor and H-bond acceptor properties, as independent variables, and the ligand $\mathrm{pKi}$ as dependent variable.

The final CoMFA model was generated employing non-cross-validated PLS analysis with the optimum number of components $(\mathrm{ONC}=5)$ to give a non-cross validated $\mathrm{r}^{2}\left(\mathrm{r}^{2}{ }_{\text {ncv }}\right)=0.96$, Standard Error of Estimate $(\mathrm{SEE})=0.298$, steric contribution $=0.593$ and electrostatic contribution $=0.407$. The model reliability thus generated was supported by bootstrapping results. All statistical parameters supporting CoMFA model are reported in Table 6.

A CoMSIA model consisting of steric, electrostatic, hydrophobic, $\mathrm{H}$-bond donor and $\mathrm{H}$-bond acceptor fields with $\mathrm{a} \mathrm{r}^{2}{ }_{\text {ncv }}=0.91, \operatorname{SEE}=0.383$, steric contribution $=0.164$, electrostatic contribution $=0.108$, hydrophobic contribution $=0.198$, H-bond acceptor contribution $=$ 0.400 and $\mathrm{H}$-bond donor contribution $=0.130$ was derived. All statistical parameters supporting CoMSIA model are reported in Table 7.

Experimental and predicted binding affinities values for the training set and test set are reported in Table 8 .

As shown in Fig. 5a (for simplicity, only the structure of compound 31, displaying the highest $\mathrm{pKi}$ value in the benzimidazole series, is depicted as representative), the steric contour map predicts favorable interaction polyhedra (green) around one of the two ethyl groups of substituent R1, and near the methylene linked to the oxygen atom in substituent R3. Unfavorable polyhedra (yellow) surround the methylene of the other ethyl group of R1, and are located near the positions 3 and 5 of the 4-ethoxyphenyl moiety. Moreover, bulkier groups than cyclopentyl result to be detrimental on substituent $\mathrm{R}$. These results are in agreement with the higher $\mathrm{pKi}$ values of $\mathbf{5 9}(\mathrm{pKi}=8.40)$ and $\mathbf{6 2}(\mathrm{pKi}=8.23)$ compared to those of $\mathbf{5 7}(\mathrm{pKi}=$ $5.87)$ and $\mathbf{6 1}(\mathrm{pKi}=7.39)$, respectively, and by the following affinity trends: $\mathbf{5 2}(\mathrm{pKi}=8.55)$ $>\mathbf{2 9}(\mathrm{pKi}=8.39)>\mathbf{5 1}(\mathrm{pKi}=8.12)>\mathbf{4 9}(\mathrm{pKi}=7.20)>\mathbf{5 8}(\mathrm{pKi}=5.36)>\mathbf{5 0}(\mathrm{pKi}=5.30)$, 
and $41(\mathrm{pKi}=8.35)>\mathbf{4 0}(\mathrm{pKi}=7.77)>39(\mathrm{pKi}=6.10)$. In addition, $31(\mathrm{pKi}=9.00)$ shows higher affinity than $\mathbf{3 2}(\mathrm{pKi}=8.43)$ and $\mathbf{3 3}(\mathrm{pKi}=7.92)$.

According to the electrostatic fields contour map of the CoMFA analysis plotted in Fig. 5b, less positive moieties would be favored (red polyhedra) in proximity of the amide (R1) and ethoxy (R3) oxygen atoms. On the other hand, more electropositive substituent are predicted to be beneficial (blue area) near the methylene of the ethoxy group (R3). The CoMSIA steric and electrostatic regions are in agreement with the CoMFA steric and electrostatic areas.

The calculated CoMSIA hydrophobic contours (Fig. 6) display favorable hydrophobic substituents (yellow polyhedra) in proximity of the R1 ethyl groups and of the cyclopentyl ring (R), and around the positions 2 and 3 of the 4-ethoxyphenyl moiety. Unfavorable areas (white) are located around the methylene between the nitrogen atom and the cyclopentyl in substituent $\mathrm{R}$, and in proximity of the R3 ethyl group. The reliability of the hydrophobic map calculation is verified by the high pKi values of $\mathbf{2 8 - 3 3}(\mathrm{pKi}=7.92-9.00)$, and by the higher affinity of $\mathbf{2 9}(\mathrm{pKi}=8.39)$ and $\mathbf{5 1 - 5 6}(\mathrm{pKi}=7.85-8.55)$ in comparison with that of $\mathbf{4 9}(\mathrm{pKi}=$ 7.20), $\mathbf{5 0}(\mathrm{pKi}=5.30)$ and $\mathbf{5 8}(\mathrm{pKi}=5.36)$. Moreover, the results are in agreement with the slightly higher pKi of $\mathbf{4 0}(\mathrm{pKi}=7.77)$ compared to that of $\mathbf{4 5}(\mathrm{pKi}=7.60)$, and with the following affinity trend: $\mathbf{4 1}(\mathrm{pKi}=8.35)>\mathbf{4 7}(\mathrm{pKi}=7.28)>\mathbf{4 3}(\mathrm{pKi}=7.37) \approx \mathbf{4 2}(\mathrm{pKi}=$ 7.36) $>\mathbf{4 6}(\mathrm{pKi}=7.24)>\mathbf{4 4}(\mathrm{pKi}=6.28)$.

Fig. 7a shows that the introduction of groups bearing $\mathrm{H}$-bond acceptor functions onto the cyclopentyl position $2(\mathrm{R})$ or onto the methylene of one of the R1 ethyl groups would be beneficial (magenta polyhedra). H-bond acceptor functions are predicted to be disfavored (green areas) in the region occupied by the methyl of the same R1 ethyl group and in proximity of the cyclopentyl position $5(\mathrm{R})$. Accordingly, H-bond donors (Fig. 7b) are predicted to be favorable (purple region) near the above-mentioned methyl and unfavorable (cyan areas) around most of the R1 ethyl groups. In addition, cyan polyhedra are positioned near the R3 methylene and methyl, and near the cyclopentyl position $2(\mathrm{R})$. These results are supported by the evidence of the high affinity levels of compounds $34(\mathrm{pKi}=7.41), \mathbf{3 6}(\mathrm{pKi}=$ 7.96) and 60-63 $(\mathrm{pKi}=7.39-8.30)$. 


\section{Model C}

To develop a single model for all compounds, 1-63 were aligned (rigid alignment of the same minimized conformation used for the generation of models A and B) by overlapping the common 1,5-disubstituted-indole or 1,5-disubstituted-benzimidazole moiety (Fig. 8). The superimposition was allowed not only by the common structural features of the two scaffolds, but also by the spatial correspondence of the molecular field maps previously elaborated for each series (models A and B). The generation of a single model (model C) for the two series of compounds offers the possibility to obtain additional information and suggestions for the design of new potent and selective analogues.

CoMFA analysis was performed dividing compounds 1-63 into a training set (1-3, 5-12, 16, 18-20, 22, 24, 25, 27-29, 31, 32, 34-42, 45, 48-52, 55, 58-61, 63 ) for model generation and into a test set $(4,13-15,17,21,23,26,30,33,43,44,46,47,53,54,56,57,62)$ for model validation. CoMFA and CoMSIA studies were developed using, respectively, CoMFA steric and electrostatic fields and CoMSIA steric, electrostatic, hydrophobic, $\mathrm{H}$-bond donor and $\mathrm{H}$ bond acceptor properties, as independent variables, and the ligand $\mathrm{pKi}$ as dependent variable.

The final CoMFA model was generated employing non-cross-validated PLS analysis with the optimum number of components $(\mathrm{ONC}=5)$ to give a non-cross validated $\mathrm{r}^{2}\left(\mathrm{r}_{\text {ncv }}^{2}\right)=0.90$, Standard Error of Estimate $(\mathrm{SEE})=0.332$, steric contribution $=0.600$ and electrostatic contribution $=0.400$. The model reliability thus generated was supported by bootstrapping results. All statistical parameters supporting CoMFA model are reported in Table 9.

A CoMSIA model consisting of steric, electrostatic, hydrophobic, $\mathrm{H}$-bond donor and $\mathrm{H}$-bond acceptor fields with $\mathrm{a}^{2}{ }_{n c v}=0.97, \operatorname{SEE}=0.267$, steric contribution $=0.201$, electrostatic contribution $=0.157$, hydrophobic contribution $=0.240, \mathrm{H}$-bond acceptor contribution $=$ 0.140 and $\mathrm{H}$-bond donor contribution $=0.262$ was derived. All statistical parameters supporting CoMSIA model are reported in Table 10.

Experimental and predicted binding affinities values for the training set and test set are reported in Table 11, while distribution of experimental and predicted pKi values for training set and test set according to CoMFA and CoMSIA models are represented in Fig. 9. 
Fig. 10-14 illustrate the model-C 3D-QSAR contour maps in the presence of the structures of compound 8 (left side, a), as representative of the 1,2,3,4-tetrahydropyrrolo[3,4- $b$ ]indole derivatives, and compound $\mathbf{3 1}$ (right side, b), as representative of the benzimidazole derivatives.

The CoMFA steric contour map (Fig. 10) displays that the green area (favorable interactions) in proximity of the position 4 of R1 piperidine in 1,2,3,4-tetrahydropyrrolo[3,4-b]indoles (Fig. 10a) and near one of the R1 ethyl groups in benzimidazoles (Fig. 10b) is wider that in models A (Fig. 2a) and B (Fig. 5a), respectively, thus suggesting the possible further occupation of that space. With regard to substituent R, the isopropyl (Fig. 10a) and the cyclopentyl (Fig. 10b) are enclosed in green polyhedra adjacent to a yellow area (unfavorable steric interactions), thus partially limiting the possibility to introduce bulkier groups. These green polyhedra were much wider in model A (Fig. 2a) and absent in model B (Fig. 5a). The large yellow area surrounding the cyclopentyl ring (Fig. 10a) appears much larger than in model A (Fig. 2a) and is located in a region not evaluated by model B (Fig. 5a). On one hand, this indicates that the introduction of much bulkier substituents R2 than cyclopentyl on the 1,2,3,4-tetrahydropyrrolo[3,4-b]indole derivatives (Fig. 10a) is not beneficial, and, on the other hand, it suggests the possibility to exploit that region for benzoimidazoles by introducing a substituent onto the benzylic methylene (Fig. 10b). The green contour below these yellow polyhedra (Fig.10a) is located in a region not taken into consideration by model A (Fig. 2a), thus suggesting the possibility to introduce a substituent onto the methylene between the pyrrole nitrogen and the carbon atom of indole position 2 , in order to increase the binding affinity of 1,2,3,4-tetrahydropyrrolo[3,4-b]indoles. The same green region surrounds the methylene of the R3 ethyl (Fig. 16b); it is larger than in model B (Fig. 5a) and it indicates that slightly bulkier groups adjacent to the oxygen atom could be effective.

According to the electrostatic fields contour map of CoMFA analysis plotted in Fig. 11, less positive moieties would be favored (red polyhedra) in proximity of one oxygen of the $\mathrm{R}$ sulfonyl group (Fig. 11a), as predicted also by model A (Fig. 2b), and in the vicinity the methylene attached to the benzoimidazole N1 (Fig. 11b), while model B (Fig. 5b) had not furnished information about substituent R. In addition, in the vicinity of the red area, more electropositive substituents are predicted to be beneficial (blue polyhedra), information missing also in model A (Fig. 2b). Concerning substituent R1, a red area is localized in the position adjacent to the amidic (CON) function (Fig. 11a and 11b), whereas it was larger in 
model A (Fig. 2b) and it was positioned in proximity of the oxygen atom in model B (Fig. 5b). In addition, an extended blue area, not appeared in models $\mathrm{A}$ and $\mathrm{B}$, is positioned across the group link to the amidic function. Differing from model A (Fig. 2b), the region of the R2 cyclopentyl presents only a red area around position 2 (Fig. 11a). The same red area indicates that the introduction of substituents, bearing less positive moieties, onto the benzylic methylene (Fig. 11b) would be beneficial, providing further information about a region unexplored by model B (Fig. 5b).

The CoMSIA steric and electrostatic contour maps are in agreement with those obtained by the CoMFA model.

The CoMSIA hydrophobic counter map (Fig. 12) displays two wide yellow areas (favorable hydrophobic interactions): the first one surrounding the alkyl portion of the R1 amidic function (Fig. 12a and 12b) [a larger area than that present in models A (Fig. 3) and B (Fig. 6)], and the second one located in the vicinity of the tetrahydropyrrole ring and enclosing part of the R2 cyclopentyl ring (Fig. 12a). At a further distance, there are white polyhedra (hydrophobic unfavorable or hydrophilic favorable) This is in agreement with model A (Fig. 3 ) and it provides suggestions (information missing in model B, Fig. 6) about the nature of the substituent that could be introduced onto the benzylic methylene of the benzoimidazole derivatives (Fig. 12b) in order to improve the binding affinity. Concerning substituent $\mathrm{R}$ (for which no indications were given by model A, Fig. 3), white polyhedra surround the sulfonyl group (Fig. 12a) and the methylene attached to the benzoimidazole N1 (Fig. 12b), while a yellow area is positioned at a short distance from one of the two methyl of the isopropyl group (Fig. 12a) and around the cyclopentyl position 3 (Fig. 12b).

The hydrogen bond acceptor contour map of the CoMSIA model (Fig. 13) shows a magenta area (favorable) near the oxygen atoms of the R sulfonyl group (Fig. 13a) and in proximity of the R cyclopentyl positions 1 and 2 (Fig. 13b), approximately in accordance with models A (Fig. 4a) and B (Fig. 7a), respectively. Concerning substituent R1, the cyan region (unfavorable), surrounding the R1 piperidine positions 3 and 4 (Fig. 13a) and one of the two R1 ethyl groups (Fig. 13b), is larger than that present in models A (Fig. 4a) and B (Fig. 7a). In addition, a magenta area (absent in model $\mathrm{A}$ ) is located in the vicinity of the $\mathrm{R} 1$ amidic function. Additional interesting information deriving from model $\mathrm{C}$ concerns the wide magenta area in the vicinity of the nitrogen tetrahydropyrrole (Fig. 13a) and the benzylic 
methylene (Fig. 13b). This highlights the possibility to introduce an hydrogen bond acceptor group onto that nitrogen (Fig. 13a) or that methylene (Fig. 13b) in order to enhance the potency of 1,2,3,4-tetrahydropyrrolo[3,4- $b$ ]indoles and benzoimidazoles, respectively.

The CoMSIA hydrogen bond donor contour map (Fig. 14) shows that a cyan area (unfavorable) is located in proximity of substituent $\mathrm{R}$, in correspondence of the magenta area in the hydrogen bond acceptor contour map (Fig. 13). Regarding substituent R1, the map of model C (Fig. 14b) resemble the map of model B (Fig. 7b), but with the difference that the purple area (favorable) enclosed in the cyan polyhedra is absent. It should be noted that model A (Fig. 4b) had not given information about substituents R1 and R2. Finally, according to model $\mathrm{C}$, a cyan region is positioned in proximity of the R2 cyclopentyl position 2 (Fig. 14a) and the oxygen atom linked to the substituent R3 (Fig. 14b).

Taking into account simultaneously all the information deriving from the model C 3D-QSAR contour maps, we have identified some structural modifications (Fig. 15 and Fig. 16) potentially useful to improve CB2 affinity of the two series of selective CB2 agonists. In detail, in the 1,2,3,4-tetrahydropyrrolo[3,4-b]indole series (Fig. 15), an alkyl- (ethyl-, isopropyl- or cyclopropyl-) -carbonyl or -sulfonyl group would seem particularly favorable as substituent R2, while a methylene linked to the position 2 of a 1,4-dimethylpyrrolidine or 4methylpyrane ring would result to be effective as substituents R. The amidic or ureic R1 groups depicted in Fig. 15 would seem to be optimal. In addition, the introduction of an alkyl or benzyl group onto the methylene between the pyrrole nitrogen and the carbon atom of indole position 2 could further enhance the binding affinity.

In the benzimidazole series (Fig. 16), an alkyl- (ethyl-, isopropyl- or cyclopropyl-) -carbonyl or -sulfonyl group, or a methylene linked to the position 2 of a 1,4-dimethylpyrrolidine or 4methylpyrane ring, would seem particularly effective as substituent R. Regarding substituent R3, the ethyl group could be more efficiently replaced by a cyclopropyl ring. The amidic or ureic R1 groups depicted in Fig. 16 would result to be particularly beneficial. Finally, the introduction of an ethoxy, isopropoxy or cyclopropoxy group onto the benzylic methylene could further increase the binding affinity. 


\section{Conclusions}

The 3D-QSAR studies here presented highlight the key structural features impacting the binding affinity of 1,2,3,4-tetrahydropyrrolo[3,4-b]indole and benzimidazole derivatives as selective CB2 agonists. Moreover, they provide useful suggestions for the design of new selective analogues with improved affinity. The models elaborated could be exploited to design new ligands and predict their binding affinity prior to synthesis.

\section{Acknowledgments}

This work was supported by University of Genova. Progetto Ateneo 2007. Fondazione Carige is gratefully acknowledged for financially supporting E.C. and S.C. 


\section{References}

1. Palmer SL, Thakur GA, Makriyannis A (2002) Cannabinergic ligands. Chem Phys Lipids 121:3-19

2. Howlett AC, Barth F, Bonner TI, Cabral G, Casellas P, Devane WA, Felder CC, Herkenham M, Mackie K, Martin BR, Mechoulam R, Pertwee RG (2002) International Union of Pharmacology. XXVII. Classification of cannabinoid receptors. Pharmacol Rev 54:161-202

3. Pertwee RG (2001) Cannabinoid receptors and pain. Prog Neurobiol 63:569-611

4. Goya P, Jagerovic N, Hernandez-Folgado L, Martin MI (2003) Cannabinoids and neuropathic pain. Mini Rev Med Chem (3):765-772

5. Calignano A, La Rana G, Piomelli D (2001) Antinociceptive activity of the endogenous fatty acid amide, palmitylethanolamide. Eur J Pharmacol 419:191-198

6. Di Marzo V, Breivogel CS, Tao Q, Bridgen DT, Razdan RK, Zimmer AM, Zimmer A, Martin BR (2000) Levels, metabolism, and pharmacological activity of anandamide in $\mathrm{CB}(1)$ cannabinoid receptor knockout mice: evidence for non- $\mathrm{CB}(1)$, non- $\mathrm{CB}(2)$ receptor-mediated actions of anandamide in mouse brain. J Neurochem 75:2434-2444

7. Hájos N, Ledent C, Freund TF (2001) Novel cannabinoid-sensitive receptor mediates inhibition of glutamatergic synaptic transmission in the hippocampus. Neuroscience $106: 1-4$

8. Whiteside GT, Lee GP, Valenzano KJ (2007) The role of the cannabinoid CB2 receptor in pain transmission and therapeutic potential of small molecule CB2 receptor agonists. Curr Med Chem 14:917-936

9. Ashton JC (2007) Cannabinoids for the treatment of inflammation. Curr Opin Investig Drugs 2007 8:373-384

10. Giblin G M, O’Shaughnessy C T, Naylor A, Mitchell WL, Eatherton AJ, Slingsby BP, Rawlings DA, Goldsmith P, Brown AJ, Haslam CP, Clayton NM, Wilson AW, Chessell IP, Wittington AR, Green R (2007) Discovery of 2-[(2,4-dichlorophenyl)amino]-N[(tetrahydro- 2H-pyran-4-yl)methyl]-4-(trifluoromethyl)- 5-pyrimidinecarboxamide, a selective CB2 receptor agonist for the treatment of inflammatory pain. J Med Chem 50:2597-2600

11. Guindon J, Hohmann AG (2008) Cannabinoid CB2 receptors:a therapeutic target for the treatment of inflammatory and neuropathic pain. Br J Pharmacol 153:319-334 
12. Khanolkar AD, Lu D, Ibrahim M, Duclos RI, Thakur GA, Malan TP, Porreca F, Veerappan V, Tian X, George C, Parrish DA, Papahatjis DP, Makriyannis A (2007) Cannabilactones:a novel class of CB2 selective agonists with peripheral analgesic activity. J Med Chem 50:6493-6500

13. Fernandez-Ruiz J, Romero J, Velasco G, Tolon RM, Ramos JA, Guzman M (2007) Trends Pharmacol Sci 28:39-45

14. Maccarrone M, Battista N, Centonze D (2007) The endocannabinoid pathway in Huntington's disease: a comparison with other neurodegenerative diseases. Prog Neurobiol 81:349-79

15. Centonze D, Finazzi-Agro A, Bernardi G, Maccarrone M (2007) The endocannabinoid system in targeting inflammatory neurodegenerative diseases. Trends Pharmacol Sci 28:180-187

16. McKallip RJ, Lombard C, Fisher M, Martin BR, Ryu S, Grant S, Nagarkatti PS, Nagarkatti M (2002) Targeting CB2 cannabinoid receptors as a novel therapy to treat malignant lymphoblastic disease. Blood 100:627-634

17. Velasco G, Galve-Roperh I, Sánchez C, Blázquez C, Guzmán M (2004) Hypothesis: cannabinoid therapy for the treatment of gliomas? Neuropharmacology 47:315-323

18. Pertwee RG (2002) Cannabinoids and multiple sclerosis. Pharmacol Ther 95:165-174

19. Ofek O, Karsak M, Leclerc N, Fogel M, Frenkel B, Wright K, Tam J, Attar-Namdar M, Kram V, Shohami E, Mechoulam R, Zimmer A (2006) Peripheral cannabinoid receptor, CB2, regulates bone mass. Bab I Proc Natl Acad Sci USA 103:696-701

20. Idris AI, Van't Hof RJ, Greig IR, Ridge SA, Baker D, Ross RA, Ralston SH (2005) Regulation of bone mass, bone loss and osteoclast activity by cannabinoid receptors. Nat Med 11:774-779

21. Lu ZL, Saldanha JW, Hulme EC (2002) Seven-transmembrane receptors: crystals clarify. Trends Pharmacol 23:140-146

22. Pagé D, Yang H, Brown W, Walpole C, Fleurent M, Fyfe M, Gaudreault F, St-Onge S (2007) New 1,2,3,4-tetrahydropyrrolo[3,4-b]indole derivatives as selective CB2 receptor agonists. Bioorg Med Chem Lett 22:6183-6187

23. Pagé D, Balaux E, Boisvert L, Liu Z, Milburn C, Tremblay M, Wei Z, Woo S, Luo X, Cheng YX, Yang H, Srivastava S, Fhou F, Brown W, Tomaszewski M, Walpole C, Hodzic L, St-Onge S, Godbout C, Salois D, Payza K (2008) Novel benzimidazole derivatives as selective CB2 agonists. Bioorg Med Chem Lett 13:3695-3700 
24. MOE: Chemical Computing Group Inc . Montreal. H3A 2R7 Canada. http://www.chemcomp.com

25. Cramer RD III, Patterson DE, Bunce JD (1989) Recent advances in comparative molecular field analysis (CoMFA). Prog Clin Biol Res 291:161-165

26. Klebe G, Abraham U, Mietzner T (1994) Molecular similarity indices in a comparative analysis (CoMSIA) of drug molecules to correlate and predict their biological activity. $\mathbf{J}$ Med Chem 37:4130-4146

27. Sybyl 7 0. Tripos Inc 1699 South Hanley Road. St Louis. Missouri. 63144. USA 


\section{Tables}

Table 1 Molecular structure of selective CB2 agonists 1-27

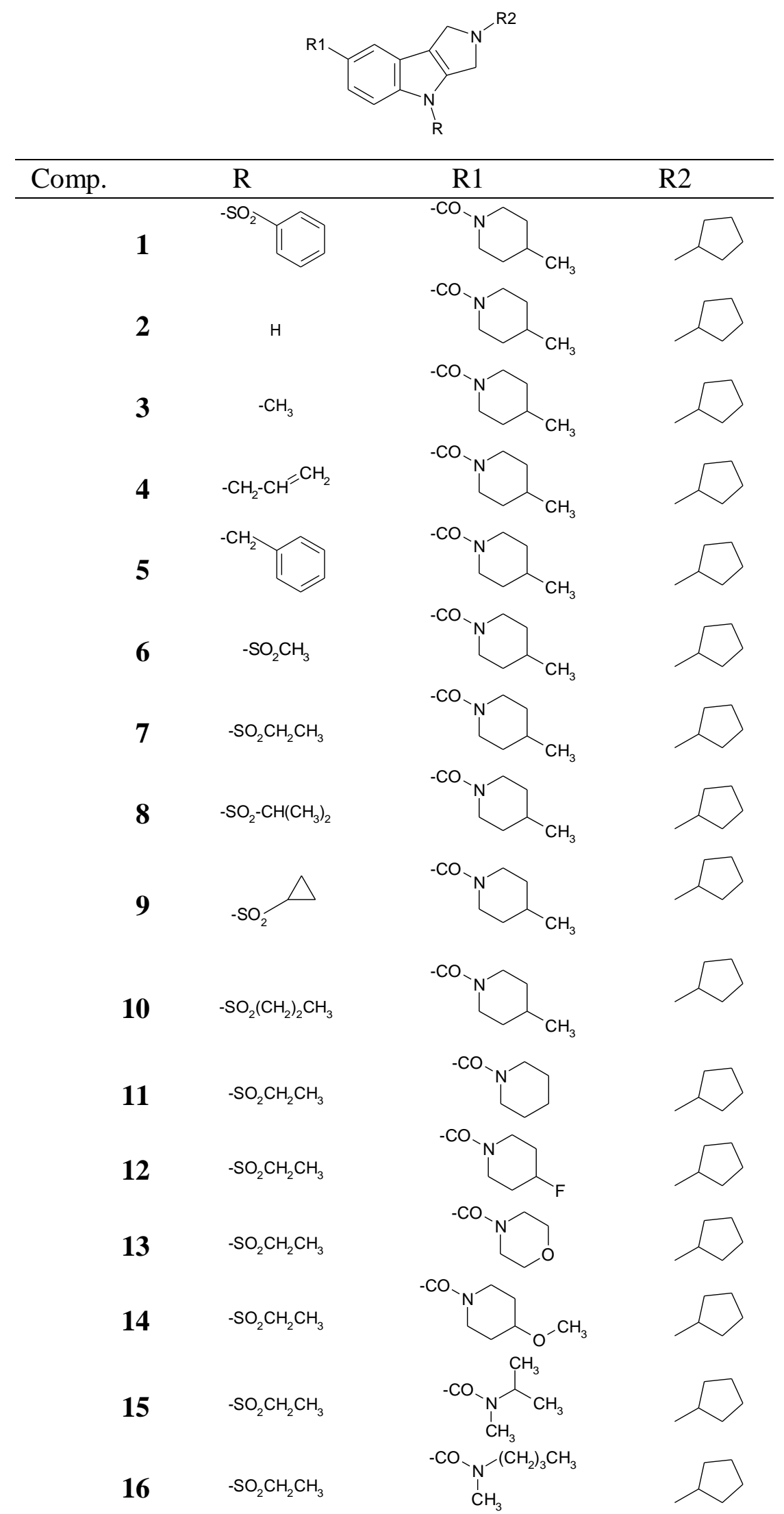


Table 1 continued

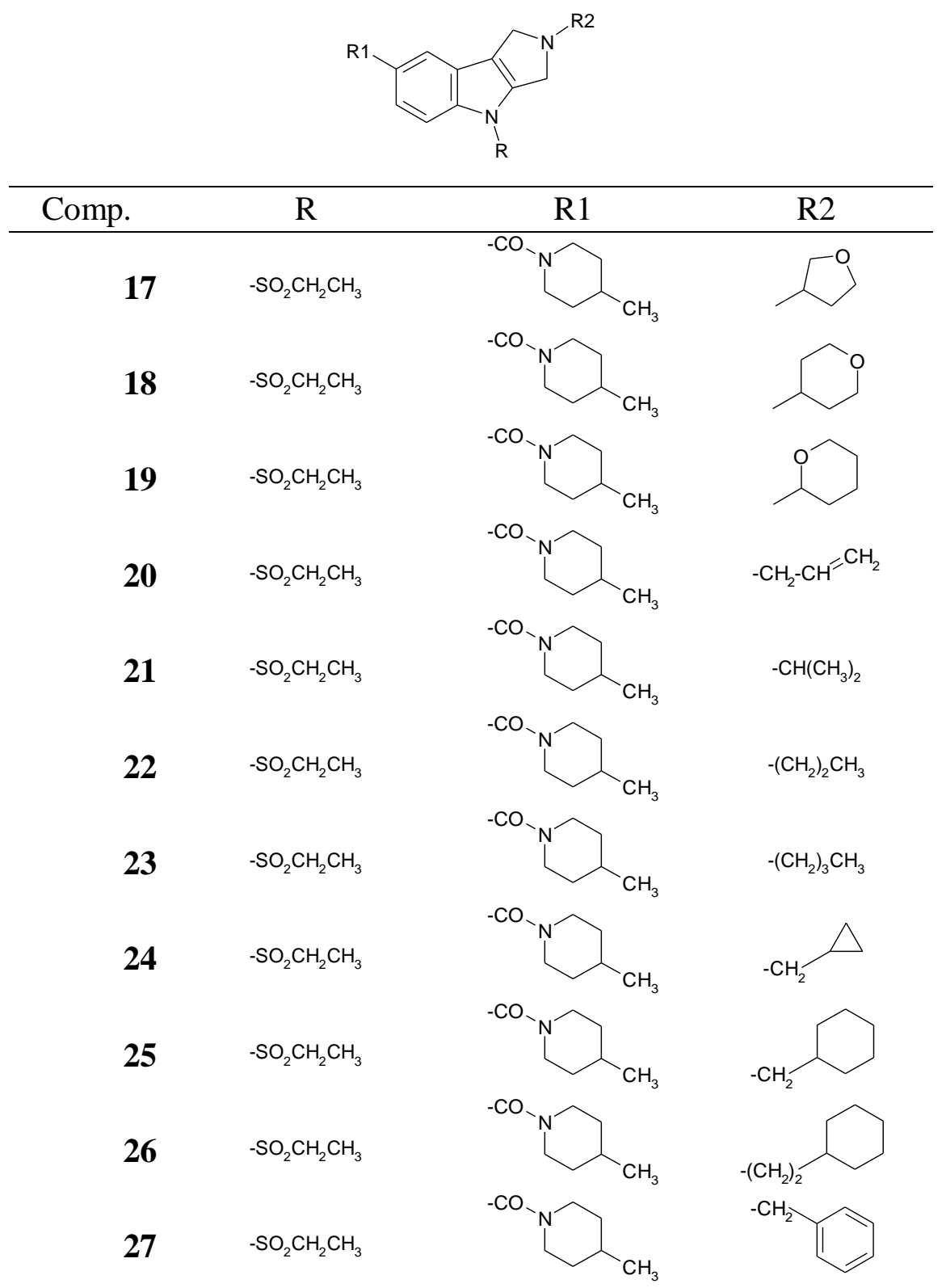


Table 2 Molecular structure of selective CB2 agonists 28-63

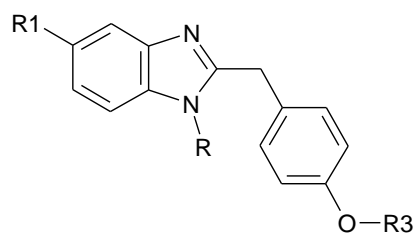

\begin{tabular}{|c|c|c|c|}
\hline Comp. & $\mathrm{R}$ & $\mathrm{R} 1$ & R3 \\
\hline 28 & $-\left(\mathrm{CH}_{2}\right)_{2} \mathrm{CH}\left(\mathrm{CH}_{3}\right)_{2}$ & $-\mathrm{CON}\left(\mathrm{CH}_{2} \mathrm{CH}_{3}\right)_{2}$ & $-\mathrm{CH}_{2} \mathrm{CH}_{3}$ \\
\hline 29 & $-\mathrm{CH}_{2}$ & $-\mathrm{CON}\left(\mathrm{CH}_{2} \mathrm{CH}_{3}\right)_{2}$ & $-\mathrm{CH}_{2} \mathrm{CH}_{3}$ \\
\hline 30 & & $-\mathrm{CON}\left(\mathrm{CH}_{2} \mathrm{CH}_{3}\right)_{2}$ & $-\mathrm{CH}_{2} \mathrm{CH}_{3}$ \\
\hline 31 & & $-\mathrm{CON}\left(\mathrm{CH}_{2} \mathrm{CH}_{3}\right)_{2}$ & $-\mathrm{CH}_{2} \mathrm{CH}_{3}$ \\
\hline 32 & & $-\mathrm{CON}\left(\mathrm{CH}_{2} \mathrm{CH}_{3}\right)_{2}$ & $-\mathrm{CH}_{2} \mathrm{CH}_{3}$ \\
\hline 33 & & $-\mathrm{CON}\left(\mathrm{CH}_{2} \mathrm{CH}_{3}\right)_{2}$ & $-\mathrm{CH}_{2} \mathrm{CH}_{3}$ \\
\hline 34 & & $-\mathrm{CON}\left(\mathrm{CH}_{2} \mathrm{CH}_{3}\right)_{2}$ & $-\mathrm{CH}_{2} \mathrm{CH}_{3}$ \\
\hline 35 & & $-\mathrm{CON}\left(\mathrm{CH}_{2} \mathrm{CH}_{3}\right)_{2}$ & $-\mathrm{CH}_{2} \mathrm{CH}_{3}$ \\
\hline 36 & $-\mathrm{CH}_{2}^{-}$ & $-\mathrm{CON}\left(\mathrm{CH}_{2} \mathrm{CH}_{3}\right)_{2}$ & $\mathrm{H}_{3}$ \\
\hline 37 & & $-\mathrm{CON}\left(\mathrm{CH}_{2} \mathrm{CH}_{3}\right)_{2}$ & $-\mathrm{CH}_{2} \mathrm{CH}_{3}$ \\
\hline 38 & & $-\mathrm{CON}\left(\mathrm{CH}_{2} \mathrm{CH}_{3}\right)_{2}$ & $-\mathrm{CH}_{2} \mathrm{CH}_{3}$ \\
\hline 39 & $-\mathrm{CH}_{2} \mathrm{CH}_{2} \mathrm{CH}\left(\mathrm{CH}_{3}\right)_{2}$ & $-\mathrm{CON}\left(\mathrm{CH}_{2} \mathrm{CH}_{3}\right)_{2}$ & $\mathrm{H}$ \\
\hline 40 & $-\mathrm{CH}_{2} \mathrm{CH}_{2} \mathrm{CH}\left(\mathrm{CH}_{3}\right)_{2}$ & $-\mathrm{CON}\left(\mathrm{CH}_{2} \mathrm{CH}_{3}\right)_{2}$ & $-\mathrm{CH}_{3}$ \\
\hline 41 & $-\mathrm{CH}_{2} \mathrm{CH}_{2} \mathrm{CH}\left(\mathrm{CH}_{3}\right)_{2}$ & $-\mathrm{CON}\left(\mathrm{CH}_{2} \mathrm{CH}_{3}\right)_{2}$ & $-\mathrm{CH}\left(\mathrm{CH}_{3}\right)_{2}$ \\
\hline 42 & $-\mathrm{CH}_{2} \mathrm{CH}_{2} \mathrm{CH}\left(\mathrm{CH}_{3}\right)_{2}$ & $-\mathrm{CON}\left(\mathrm{CH}_{2} \mathrm{CH}_{3}\right)_{2}$ & \\
\hline 43 & $-\mathrm{CH}_{2} \mathrm{CH}_{2} \mathrm{CH}\left(\mathrm{CH}_{3}\right)_{2}$ & $-\mathrm{CON}\left(\mathrm{CH}_{2} \mathrm{CH}_{3}\right)_{2}$ & \\
\hline 44 & $-\mathrm{CH}_{2} \mathrm{CH}_{2} \mathrm{CH}\left(\mathrm{CH}_{3}\right)_{2}$ & $-\mathrm{CON}\left(\mathrm{CH}_{2} \mathrm{CH}_{3}\right)_{2}$ & \\
\hline 45 & $-\mathrm{CH}_{2} \mathrm{CH}_{2} \mathrm{CH}\left(\mathrm{CH}_{3}\right)_{2}$ & $-\mathrm{CON}\left(\mathrm{CH}_{2} \mathrm{CH}_{3}\right)_{2}$ & $-\mathrm{CF}_{3}$ \\
\hline 46 & $-\mathrm{CH}_{2} \mathrm{CH}_{2} \mathrm{CH}\left(\mathrm{CH}_{3}\right)_{2}$ & $-\mathrm{CON}\left(\mathrm{CH}_{2} \mathrm{CH}_{3}\right)_{2}$ & \\
\hline 47 & $-\mathrm{CH}_{2} \mathrm{CH}_{2} \mathrm{CH}\left(\mathrm{CH}_{3}\right)_{2}$ & $-\mathrm{CON}\left(\mathrm{CH}_{2} \mathrm{CH}_{3}\right)_{2}$ & $-\mathrm{Cr}$ \\
\hline 48 & $-\mathrm{CH}_{2} \mathrm{CH}_{2} \mathrm{CH}\left(\mathrm{CH}_{3}\right)_{2}$ & $-\mathrm{CON}\left(\mathrm{CH}_{2} \mathrm{CH}_{3}\right)_{2}$ & \\
\hline
\end{tabular}


Table 2 continued

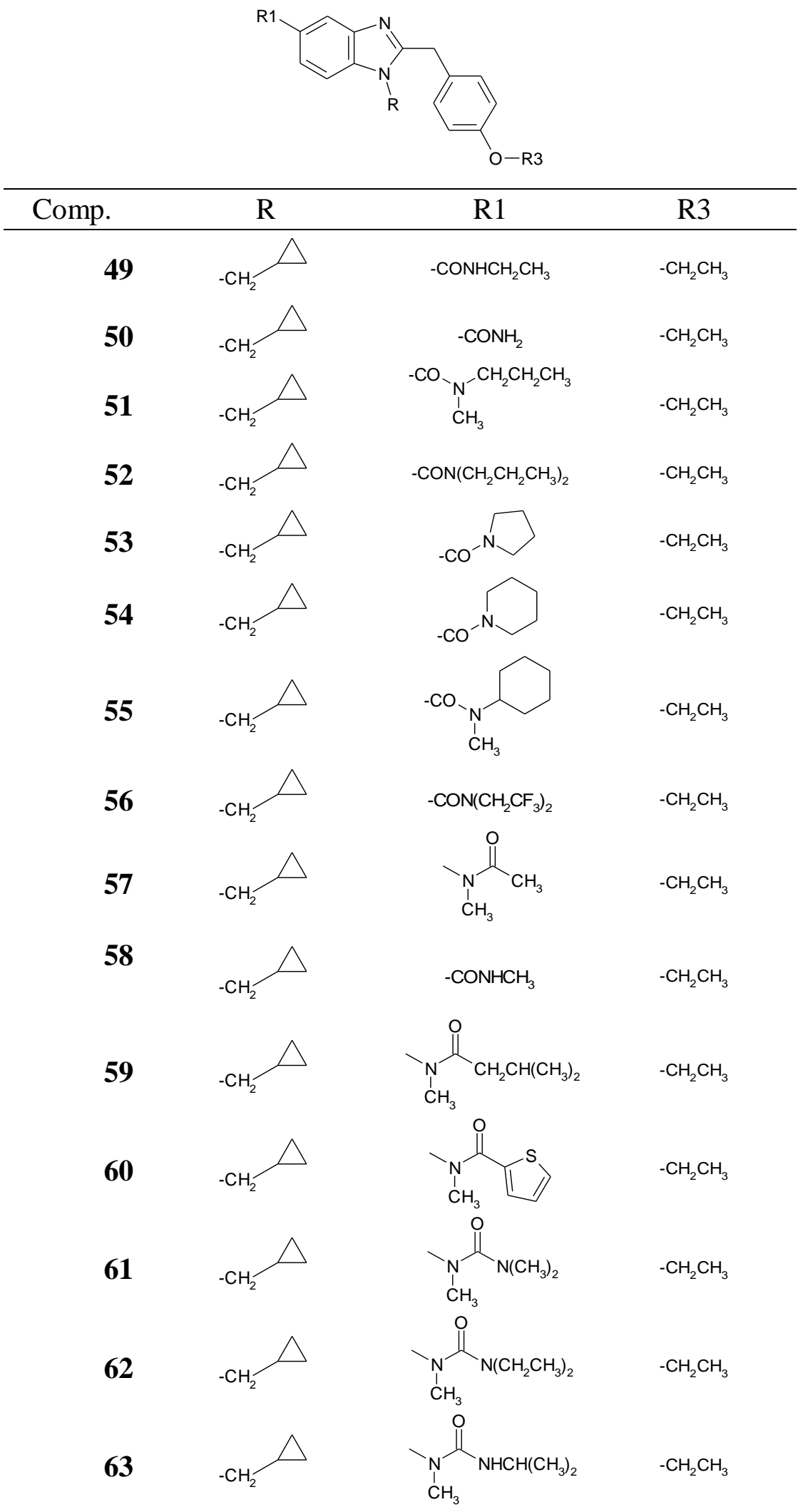


Table 3 Summary of Model A CoMFA results

\begin{tabular}{|c|c|}
\hline No. compounds & 19 \\
\hline Optimal number of components (ONC) & 3 \\
\hline Leave one out $r^{2}\left(r^{2}{ }_{l o o}\right)$ & 0.515 \\
\hline Cross-validated $r^{2}\left(r_{c v}^{2}\right)$ & 0.610 \\
\hline Std. error of estimate (SEE) & 0.254 \\
\hline Non cross-validated $r^{2}\left(r^{2}\right.$ cv $)$ & 0.942 \\
\hline F value & 98.827 \\
\hline Steric contribution & 0.432 \\
\hline Electrostatic contribution & 0.568 \\
\hline Bootstrap $r^{2}\left(r_{\text {boot }}^{2}\right)$ & 0.96 \\
\hline Standard error of estimate $r_{\text {boot }}^{2}\left(\operatorname{SEE} r_{\text {boot }}^{2}\right)$ & 0.242 \\
\hline Test set $r^{2}\left(r_{\text {pred }}^{2}\right)$ & 0.85 \\
\hline
\end{tabular}


Table 4 Summary of Model A CoMSIA results

\begin{tabular}{|c|c|}
\hline No. compounds & 19 \\
\hline Optimal number of components (ONC) & 3 \\
\hline Leave one out $r^{2}\left(r^{2}{ }_{\text {loo }}\right)$ & 0.545 \\
\hline Cross-validated $r^{2}\left(r_{c v}^{2}\right)$ & 0.624 \\
\hline Std. error of estimate (SEE) & 0.232 \\
\hline Non cross-validated $r^{2}\left(r_{n c v}^{2}\right)$ & 0.97 \\
\hline F value & 177.833 \\
\hline Steric contribution & 0.176 \\
\hline Electrostatic contribution & 0.253 \\
\hline Hydrophobic contribution & 0.232 \\
\hline H-bond acceptor contribution & 0.194 \\
\hline H-bond donor contribution & 0.144 \\
\hline Bootstrap $r^{2}\left(r^{2}{ }_{\text {boot }}\right)$ & 0.93 \\
\hline Standard error of estimate $r_{\text {boot }}^{2}\left(\right.$ SEE $\left.r_{\text {boot }}^{2}\right)$ & 0.229 \\
\hline Test set $\mathrm{r}^{2}\left(\mathrm{r}_{\text {pred }}^{2}\right)$ & 0.88 \\
\hline
\end{tabular}


Table 5 Experimental and predicted pKi values of compounds 1-27 according to model A

\begin{tabular}{|c|c|c|c|c|c|}
\hline \multirow[b]{2}{*}{ Compound } & \multirow[b]{2}{*}{ Exp. pKi } & \multicolumn{2}{|c|}{ CoMFA Model } & \multicolumn{2}{|c|}{ CoMSIA Model } \\
\hline & & Pred. pKi & Residual & Pred. pKi & Residual \\
\hline 1 & 7.75 & 7.75 & 0.00 & 7.88 & -0.13 \\
\hline 2 & 5.33 & 6.01 & -0.68 & 5.34 & -0.01 \\
\hline 3 & 7.07 & 6.73 & 0.34 & 7.02 & 0.05 \\
\hline $4^{a}$ & 7.63 & 7.37 & 0.26 & 7.89 & -0.26 \\
\hline 5 & 6.97 & 7.11 & -0.14 & 6.80 & 0.17 \\
\hline 6 & 8.10 & 8.04 & 0.06 & 7.96 & 0.14 \\
\hline 7 & 8.15 & 7.90 & 0.25 & 7.96 & 0.19 \\
\hline 8 & 8.38 & 8.15 & 0.24 & 8.09 & 0.29 \\
\hline 9 & 8.03 & 8.18 & -0.15 & 8.05 & -0.02 \\
\hline 10 & 7.65 & 7.96 & -0.31 & 7.98 & -0.33 \\
\hline 11 & 7.76 & 7.75 & 0.01 & 7.78 & -0.02 \\
\hline 12 & 7.35 & 7.19 & 0.16 & 7.19 & 0.16 \\
\hline $13^{a}$ & 6.51 & 6.27 & 0.24 & 6.25 & 0.26 \\
\hline $14^{a}$ & 7.56 & 7.33 & 0.23 & 7.20 & 0.36 \\
\hline $15^{a}$ & 6.97 & 7.12 & -0.15 & 7.38 & -0.41 \\
\hline 16 & 7.65 & 7.33 & 0.32 & 7.41 & 0.25 \\
\hline $17^{a}$ & 7.56 & 7.04 & 0.52 & 7.22 & 0.34 \\
\hline 18 & 6.67 & 6.52 & 0.15 & 6.59 & 0.08 \\
\hline 19 & 7.75 & 7.74 & 0.01 & 7.85 & -0.09 \\
\hline 20 & 8.19 & 8.43 & -0.24 & 8.33 & -0.14 \\
\hline $21^{a}$ & 8.05 & 7.77 & 0.28 & 8.14 & -0.09 \\
\hline 22 & 7.95 & 7.84 & 0.11 & 7.95 & 0.00 \\
\hline $\mathbf{2 3}^{a}$ & 7.77 & 7.50 & 0.27 & 7.67 & 0.10 \\
\hline 24 & 8.20 & 8.01 & 0.19 & 7.62 & 0.58 \\
\hline 25 & 6.03 & 6.01 & 0.02 & 6.43 & -0.40 \\
\hline $26^{a}$ & 5.70 & 6.02 & -0.32 & 5.82 & -0.12 \\
\hline 27 & 7.43 & 7.48 & -0.05 & 7.34 & 0.09 \\
\hline
\end{tabular}


Table 6 Summary of Model B CoMFA results

\begin{tabular}{|l|c|}
\hline No. compounds & 25 \\
\hline Optimal number of components $(\mathrm{ONC})$ & 5 \\
\hline Leave one out $\mathrm{r}^{2}\left(\mathrm{r}^{2}{ }_{\text {loo }}\right)$ & 0.510 \\
\hline Cross-validated $\mathrm{r}^{2}\left(\mathrm{r}^{2}{ }_{\mathrm{cv}}\right)$ & 0.543 \\
\hline Std. error of estimate $(\mathrm{SEE})$ & 0.298 \\
\hline Non cross-validated $\mathrm{r}^{2}\left(\mathrm{r}^{2}{ }_{\mathrm{ncv}}\right)$ & 0.96 \\
\hline F value & 108.104 \\
\hline Steric contribution & 0.593 \\
\hline Electrostatic contribution & 0.407 \\
\hline Bootstrap $\mathrm{r}^{2}\left(\mathrm{r}^{2}{ }_{\text {boot }}\right)$ & 0.95 \\
\hline Standard error of estimate $\mathrm{r}^{2}{ }_{\text {boot }}\left(\mathrm{SEE} \mathrm{r}_{\text {boot }}\right)$ & 0.210 \\
\hline Test set $\mathrm{r}^{2}\left(\mathrm{r}^{2}{ }_{\text {pred }}\right)$ & 0.93 \\
\hline
\end{tabular}


Table 7 Summary of Model B CoMSIA results

\begin{tabular}{|c|c|}
\hline No. compounds & 25 \\
\hline Optimal number of components (ONC) & 4 \\
\hline Leave one out $r^{2}\left(r_{\text {loo }}^{2}\right)$ & 0.496 \\
\hline Cross-validated $r^{2}\left(r_{c v}^{2}\right)$ & 0.512 \\
\hline Std. error of estimate (SEE) & 0.383 \\
\hline Non cross-validated $r^{2}\left(r^{2}{ }_{n c v}\right)$ & 0.91 \\
\hline F value & 60.667 \\
\hline Steric contribution & 0.164 \\
\hline Electrostatic contribution & 0.108 \\
\hline Hydrophobic contribution & 0.198 \\
\hline H-bond acceptor contribution & 0.400 \\
\hline H-bond donor contribution & 0.130 \\
\hline Bootstrap $r^{2}\left(r^{2}{ }_{\text {boot }}\right)$ & 0.91 \\
\hline Standard error of estimate $r_{\text {boot }}^{2}\left(\right.$ SEE $r^{2}$ boot $)$ & 0.223 \\
\hline Test set $r^{2}\left(r_{\text {pred }}^{2}\right)$ & 0.76 \\
\hline
\end{tabular}


Table 8 Experimental and predicted pKi values of compounds 28-63 according to model B

\begin{tabular}{|c|c|c|c|c|c|}
\hline \multirow[b]{2}{*}{ Compound } & \multirow[b]{2}{*}{ Exp. pKi } & \multicolumn{2}{|c|}{ CoMFA Model } & \multicolumn{2}{|c|}{ CoMSIA Model } \\
\hline & & Pred. pKi & Residual & Pred. pKi & Residual \\
\hline 28 & 8.35 & 8.48 & -0.13 & 8.38 & -0.03 \\
\hline 29 & 8.39 & 8.42 & -0.03 & 8.52 & -0.13 \\
\hline $30^{a}$ & 8.80 & 8.62 & 0.18 & 8.62 & 0.18 \\
\hline 31 & 9.00 & 8.80 & 0.20 & 8.79 & 0.21 \\
\hline 32 & 8.43 & 8.67 & -0.24 & 8.69 & -0.26 \\
\hline $3^{a}$ & 7.92 & 7.63 & 0.30 & 7.65 & 0.27 \\
\hline 34 & 7.41 & 7.30 & 0.12 & 7.54 & -0.13 \\
\hline 35 & 7.80 & 7.91 & -0.11 & 8.00 & -0.20 \\
\hline 36 & 7.96 & 7.70 & 0.26 & 7.84 & 0.13 \\
\hline 37 & 8.41 & 8.02 & 0.39 & 8.53 & -0.12 \\
\hline 38 & 5.53 & 6.20 & -0.67 & 5.63 & -0.10 \\
\hline 39 & 6.10 & 6.29 & -0.19 & 6.67 & -0.57 \\
\hline 40 & 7.77 & 7.33 & 0.44 & 7.85 & -0.08 \\
\hline 41 & 8.35 & 8.37 & -0.02 & 8.22 & 0.13 \\
\hline 42 & 7.36 & 7.47 & -0.11 & 8.26 & -0.90 \\
\hline $43^{a}$ & 7.37 & 7.66 & -0.29 & 7.92 & -0.55 \\
\hline $44^{a}$ & 6.28 & 6.40 & -0.12 & 6.91 & -0.63 \\
\hline 45 & 7.60 & 6.39 & -0.11 & 6.71 & -0.43 \\
\hline $46^{a}$ & 7.24 & 7.51 & 0.09 & 7.82 & -0.22 \\
\hline $47^{a}$ & 7.28 & 7.09 & 0.15 & 7.32 & -0.08 \\
\hline 48 & 8.31 & 7.09 & 0.15 & 7.62 & -0.38 \\
\hline 49 & 7.20 & 7.62 & -0.34 & 8.01 & -0.73 \\
\hline 50 & 5.30 & 8.59 & -0.28 & 8.27 & 0.04 \\
\hline 51 & 8.12 & 7.38 & -0.18 & 7.19 & 0.01 \\
\hline 52 & 8.55 & 5.34 & -0.04 & 5.79 & -0.49 \\
\hline $53^{a}$ & 7.85 & 7.85 & 0.27 & 7.93 & 0.19 \\
\hline $54^{a}$ & 8.16 & 8.64 & -0.09 & 8.12 & 0.43 \\
\hline 55 & 7.96 & 7.68 & 0.17 & 7.59 & 0.26 \\
\hline $56^{a}$ & 8.25 & 8.03 & -0.18 & 7.59 & 0.26 \\
\hline $57^{a}$ & 5.87 & 8.01 & 0.15 & 7.82 & 0.34 \\
\hline 58 & 5.36 & 7.85 & 0.11 & 8.21 & -0.25 \\
\hline 59 & 8.40 & 8.10 & 0.15 & 7.73 & 0.52 \\
\hline 60 & 8.30 & 5.95 & -0.08 & 6.02 & -0.15 \\
\hline 61 & 7.39 & 6.12 & -0.25 & 6.10 & -0.23 \\
\hline
\end{tabular}




\begin{tabular}{|r|r|l|l|l|l|}
\hline $\mathbf{6 2}^{\boldsymbol{a}}$ & 8.23 & 5.23 & 0.13 & 5.40 & -0.04 \\
\hline $\mathbf{6 3}$ & 8.24 & 8.57 & -0.17 & 8.54 & -0.14 \\
\hline
\end{tabular}

$a$ Test set compounds 
Table 9 Summary of Model C CoMFA results

\begin{tabular}{|l|c|}
\hline No. compounds & 44 \\
\hline Optimal number of components (ONC) & 5 \\
\hline Leave one out $\mathrm{r}^{2}\left(\mathrm{r}^{2}{ }_{\text {loo }}\right)$ & 0.562 \\
\hline Cross-validated $\mathrm{r}^{2}\left(\mathrm{r}_{\mathrm{cv}}\right)$ & 0.640 \\
\hline Std. error of estimate $(\mathrm{SEE})$ & 0.332 \\
\hline Non cross-validated $\mathrm{r}^{2}\left(\mathrm{r}^{2}{ }_{\text {ncv }}\right)$ & 0.90 \\
\hline F value & 81.402 \\
\hline Steric contribution & 0.600 \\
\hline Electrostatic contribution & 0.400 \\
\hline Bootstrap ${ }^{2}\left(\mathrm{r}^{2}{ }_{\text {boot }}\right)$ & 0.95 \\
\hline Standard error of estimate $\mathrm{r}^{2}$ boot $\left(\mathrm{SEE} \mathrm{r}^{2}{ }_{\text {boot }}\right)$ & 0.241 \\
\hline Test set $\mathrm{r}^{2}\left(\mathrm{r}^{2}{ }_{\text {pred }}\right)$ & 0.89 \\
\hline
\end{tabular}


Table 10 Summary of Model C CoMSIA results

\begin{tabular}{|c|c|}
\hline No. compounds & 44 \\
\hline Optimal number of components (ONC) & 6 \\
\hline Leave one out $r^{2}\left(r^{2}{ }_{100}\right)$ & 0.593 \\
\hline Cross-validated $r^{2}\left(r_{c v}^{2}\right)$ & 0.680 \\
\hline Std. error of estimate (SEE) & 0.267 \\
\hline Non cross-validated $r^{2}\left(r_{n c v}^{2}\right)$ & 0.97 \\
\hline F value & 106.064 \\
\hline Steric contribution & 0.201 \\
\hline Electrostatic contribution & 0.157 \\
\hline Hydrophobic contribution & 0.240 \\
\hline H-bond acceptor contribution & 0.140 \\
\hline H-bond donor contribution & 0.262 \\
\hline Bootstrap $r^{2}\left(r^{2}\right.$ boot $)$ & 0.94 \\
\hline Standard error of estimate $r_{\text {boot }}^{2}\left(\operatorname{SEE} r^{2}{ }_{\text {boot }}\right)$ & 0.273 \\
\hline Test set $r^{2}\left(r_{\text {pred }}^{2}\right)$ & 0.93 \\
\hline
\end{tabular}


Table 11 Experimental and predicted $\mathrm{pKi}$ values of compounds 1-63, according to model $\mathrm{C}$

\begin{tabular}{|c|c|c|c|c|c|}
\hline \multirow[b]{2}{*}{ Compound } & \multirow[b]{2}{*}{ Exp.pKi } & \multicolumn{2}{|c|}{ CoMFA Model } & \multicolumn{2}{|c|}{ CoMSIA Model } \\
\hline & & Pred. pKi & Residual & Pred. pKi & Residual \\
\hline 1 & 7.75 & 7.67 & 0.08 & 7.86 & -0.11 \\
\hline 2 & 5.33 & 5.41 & -0.08 & 4.99 & 0.34 \\
\hline 3 & 7.07 & 6.82 & 0.25 & 7.22 & -0.15 \\
\hline $4^{a}$ & 7.63 & 7.56 & 0.07 & 7.52 & 0.12 \\
\hline 5 & 6.97 & 6.68 & 0.29 & 6.88 & 0.09 \\
\hline 6 & 8.10 & 7.95 & 0.15 & 7.99 & 0.11 \\
\hline 7 & 8.15 & 7.92 & 0.23 & 7.88 & 0.27 \\
\hline 8 & 8.38 & 8.47 & -0.09 & 8.17 & 0.21 \\
\hline 9 & 8.03 & 7.95 & 0.08 & 8.00 & 0.03 \\
\hline 10 & 7.65 & 7.65 & 0.00 & 8.01 & -0.36 \\
\hline 11 & 7.76 & 7.64 & 0.12 & 7.64 & 0.12 \\
\hline 12 & 7.35 & 7.11 & 0.24 & 7.24 & 0.11 \\
\hline $13^{a}$ & 6.51 & 6.78 & -0.27 & 6.63 & -0.12 \\
\hline $14^{a}$ & 7.56 & 7.25 & 0.31 & 7.29 & 0.27 \\
\hline $15^{a}$ & 6.97 & 6.69 & 0.28 & 7.24 & -0.27 \\
\hline 16 & 7.65 & 7.54 & 0.11 & 7.53 & 0.12 \\
\hline $17^{a}$ & 7.56 & 7.42 & 0.14 & 7.22 & 0.34 \\
\hline 18 & 6.67 & 6.82 & -0.15 & 6.75 & -0.08 \\
\hline 19 & 7.75 & 7.62 & 0.13 & 7.79 & -0.04 \\
\hline 20 & 8.19 & 8.37 & -0.18 & 8.21 & -0.02 \\
\hline $21^{a}$ & 8.05 & 8.22 & -0.16 & 7.82 & 0.23 \\
\hline 22 & 7.95 & 8.31 & -0.36 & 7.93 & 0.02 \\
\hline $\mathbf{2 3}^{a}$ & 7.77 & 7.45 & 0.32 & 7.84 & -0.07 \\
\hline 24 & 8.20 & 8.37 & -0.17 & 7.91 & 0.29 \\
\hline 25 & 6.03 & 6.02 & 0.01 & 6.21 & -0.18 \\
\hline $26^{a}$ & 5.70 & 5.91 & -0.21 & 5.89 & -0.19 \\
\hline 27 & 7.43 & 7.52 & -0.09 & 7.23 & 0.20 \\
\hline 28 & 8.35 & 8.38 & -0.03 & 8.23 & 0.12 \\
\hline 29 & 8.39 & 8.15 & 0.24 & 8.47 & -0.08 \\
\hline $30^{a}$ & 8.80 & 8.42 & 0.39 & 8.62 & 0.18 \\
\hline 31 & 9.00 & 8.64 & 0.36 & 8.82 & 0.18 \\
\hline
\end{tabular}


Table 11 continued

\begin{tabular}{|c|c|c|c|c|c|}
\hline \multirow[b]{2}{*}{ Compound } & \multirow[b]{2}{*}{ Exp. pKi } & \multicolumn{2}{|c|}{ CoMFA Model } & \multicolumn{2}{|c|}{ CoMSIA Model } \\
\hline & & Pred. pKi & Residual & Pred. pKi & Residual \\
\hline 32 & 8.43 & 8.54 & -0.11 & 8.62 & -0.19 \\
\hline $3^{a}$ & 7.92 & 7.67 & 0.25 & 7.71 & 0.21 \\
\hline 34 & 7.41 & 7.62 & -0.21 & 7.52 & -0.11 \\
\hline 35 & 7.80 & 7.68 & 0.12 & 7.97 & -0.17 \\
\hline 36 & 7.96 & 7.87 & 0.09 & 7.81 & 0.15 \\
\hline 37 & 8.41 & 7.87 & 0.54 & 8.50 & -0.09 \\
\hline 38 & 5.53 & 5.78 & -0.25 & 5.69 & -0.16 \\
\hline 39 & 6.10 & 6.72 & -0.62 & 5.86 & 0.24 \\
\hline 40 & 7.77 & 7.48 & 0.29 & 7.50 & 0.27 \\
\hline 41 & 8.35 & 8.03 & 0.32 & 8.69 & -0.34 \\
\hline 42 & 7.36 & 7.73 & -0.37 & 7.63 & -0.27 \\
\hline $43^{a}$ & 7.37 & 7.68 & -0.31 & 7.56 & -0.19 \\
\hline $44^{a}$ & 6.28 & 6.41 & -0.13 & 6.26 & 0.02 \\
\hline 45 & 7.60 & 7.34 & 0.26 & 7.48 & 0.12 \\
\hline $46^{a}$ & 7.24 & 7.18 & 0.06 & 7.35 & -0.11 \\
\hline $47^{a}$ & 7.28 & 7.76 & -0.48 & 7.54 & -0.26 \\
\hline 48 & 8.31 & 8.34 & -0.03 & 7.99 & 0.32 \\
\hline 49 & 7.20 & 6.78 & 0.42 & 6.98 & 0.22 \\
\hline 50 & 5.30 & 5.32 & -0.02 & 5.32 & -0.02 \\
\hline 51 & 8.12 & 8.09 & 0.03 & 8.20 & -0.08 \\
\hline 52 & 8.55 & 8.84 & -0.29 & 8.59 & -0.04 \\
\hline $53^{a}$ & 7.85 & 7.54 & 0.31 & 7.95 & -0.10 \\
\hline $54^{a}$ & 8.16 & 7.73 & 0.44 & 8.45 & -0.29 \\
\hline 55 & 7.96 & 8.32 & -0.36 & 8.02 & -0.06 \\
\hline $56^{a}$ & 8.25 & 8.21 & 0.04 & 7.99 & 0.26 \\
\hline $57^{a}$ & 5.87 & 6.22 & -0.35 & 6.11 & -0.24 \\
\hline 58 & 5.36 & 5.30 & 0.06 & 5.60 & -0.24 \\
\hline 59 & 8.40 & 8.48 & -0.08 & 8.53 & -0.13 \\
\hline 60 & 8.30 & 7.89 & 0.41 & 8.18 & 0.12 \\
\hline 61 & 7.39 & 7.50 & -0.11 & 7.64 & -0.25 \\
\hline $62^{a}$ & 8.23 & 8.14 & 0.09 & 7.90 & 0.33 \\
\hline 63 & 8.24 & 8.37 & -0.13 & 7.98 & 0.26 \\
\hline
\end{tabular}




\section{Figure captions}

Fig. 1 Chemical structure of selective CB2 agonists 8 and $\mathbf{3 1}$ (showing the highest pKi values in the 1,2,3,4-tetrahydropyrrolo[3,4- $b]$ indole series and in the benzimidazole series, respectively). The common 1,5-disubstituted-indole or -benzimidazole scaffold is depicted in blue

Fig. 2 Contour maps of model A CoMFA steric regions (a) (green, favored; yellow, disfavored) and CoMFA electrostatic areas (b) are displayed around compound $\mathbf{8}$. Blue regions are favorable for more positively charged groups; red regions are favorable for less positively charged groups. Ligands are depicted in stick mode and colored by atom type

Fig. 3 Contour maps of model A CoMSIA hydrophobic regions (yellow, favored; white, disfavored) are depicted around compounds $\mathbf{8}$, shown in stick mode and colored by atom type

Fig. 4 Model A CoMSIA hydrogen bond acceptor polyhedra (a) and hydrogen bond donor polyhedra (b) are shown around compounds $\mathbf{8}$ depicted in stick mode and colored by atom type. H-bond acceptor groups:magenta, favored; green, disfavored. H-bond donor groups:purple, favored; cyan, disfavored

Fig. 5 Contour maps of model B CoMFA steric regions (a) (green, favored; yellow, disfavored) and CoMFA electrostatic areas (b) are displayed around compound $\mathbf{3 1 .}$ Blue regions are favorable for more positively charged groups; red regions are favorable for less positively charged groups. Ligands are depicted in stick mode and colored by atom type

Fig. 6 Contour maps of model B CoMSIA hydrophobic regions (yellow, favored; white, disfavored) are depicted around compounds 31, shown in stick mode and colored by atom type

Fig. 7 Model B CoMSIA hydrogen bond acceptor polyhedra (a) and hydrogen bond donor polyhedra (b) are shown around compounds $\mathbf{3 1}$ depicted in stick mode and colored 
by atom type. H-bond acceptor groups:magenta, favored; green, disfavored. H-bond donor groups:purple, favored; cyan, disfavored

Fig. 8 Alignment of 1-63, used in final CoMFA and CoMSIA analyses (Model C)

Fig. 9 Distribution of experimental and predicted pKi values for training set compounds according to model $\mathrm{C}$ CoMFA analysis (a), for test set compounds according to model C CoMFA analysis (b), for training set compounds according to model $\mathrm{C}$ CoMSIA analysis (c), and for test set compounds according to model C CoMSIA analysis (d)

Fig. 10 Contour maps of model C CoMFA steric regions (green, favored; yellow, disfavored) are displayed around compound 8 (a), and 31 (b). Ligands are depicted in stick mode and colored by atom type

Fig. 11 Contour maps of model C CoMFA electrostatic regions are shown around compounds 8 (a) and $\mathbf{3 1}$ (b). Blue regions are favorable for more positively charged groups; red regions are favorable for less positively charged groups

Fig. 12 Contour maps of model C CoMSIA hydrophobic regions (yellow, favored; white, disfavored) are shown around compounds 8 (a) and $\mathbf{3 1}$ (b). Ligands are shown in stick mode and colored by atom type

Fig. 13 Model C CoMSIA hydrogen bond acceptor polyhedra are shown around compounds 8 (a) and $\mathbf{3 1}$ (b), depicted in stick mode and colored by atom type. Hbond acceptor groups:magenta, favored; green, disfavored

Fig. 14 Model C CoMSIA hydrogen bond donor polyhedra are shown around compounds 8 (a) and 31 (b), depicted in stick mode and colored by atom type. H-bond donor groups:purple, favored; cyan, disfavored

Fig. 15 Structural modifications potentially useful to increase the binding affinity of the selective CB2-agonist 1,2,3,4-tetrahydropyrrolo[3,4-b]indole derivatives 
Fig. 16 Structural modifications potentially useful to increase the binding affinity of the selective CB2-agonist benzimidazole derivatives 


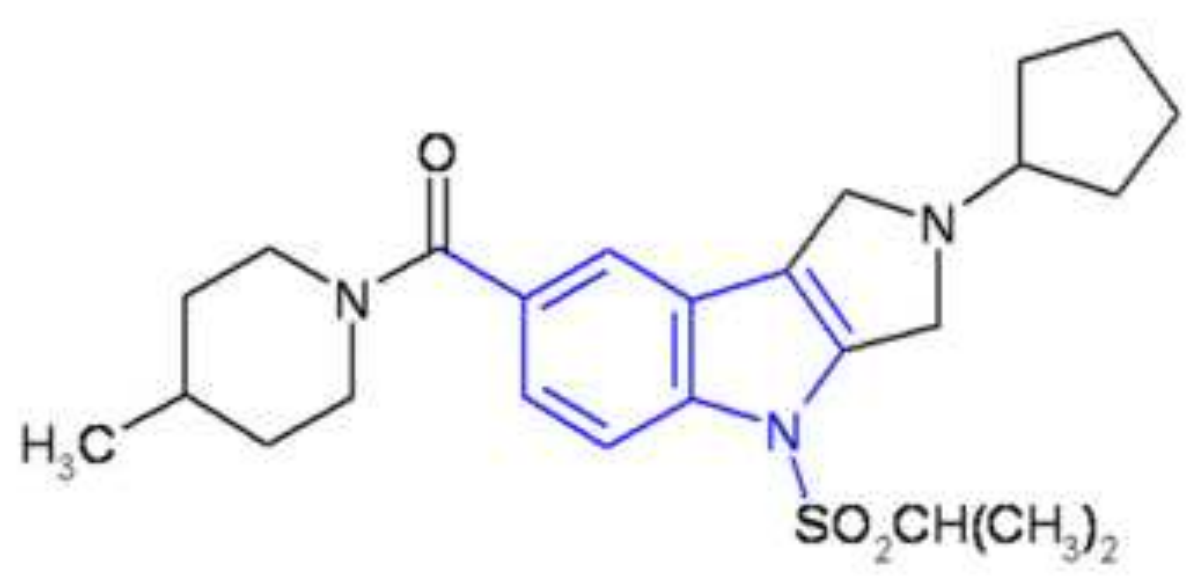

8

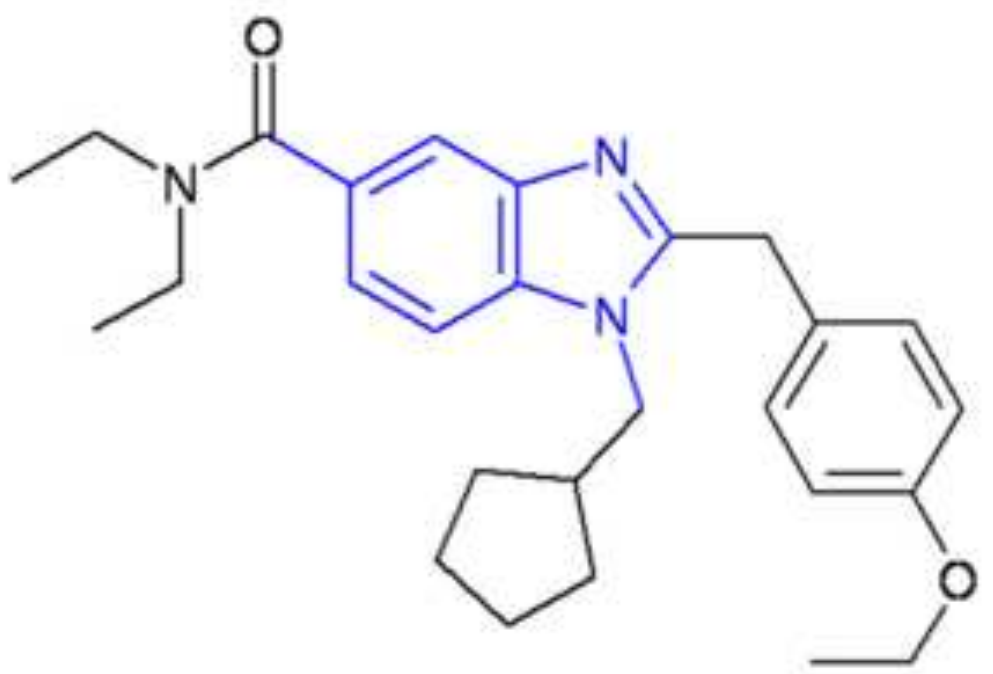

31 
Click here to download high resolution image

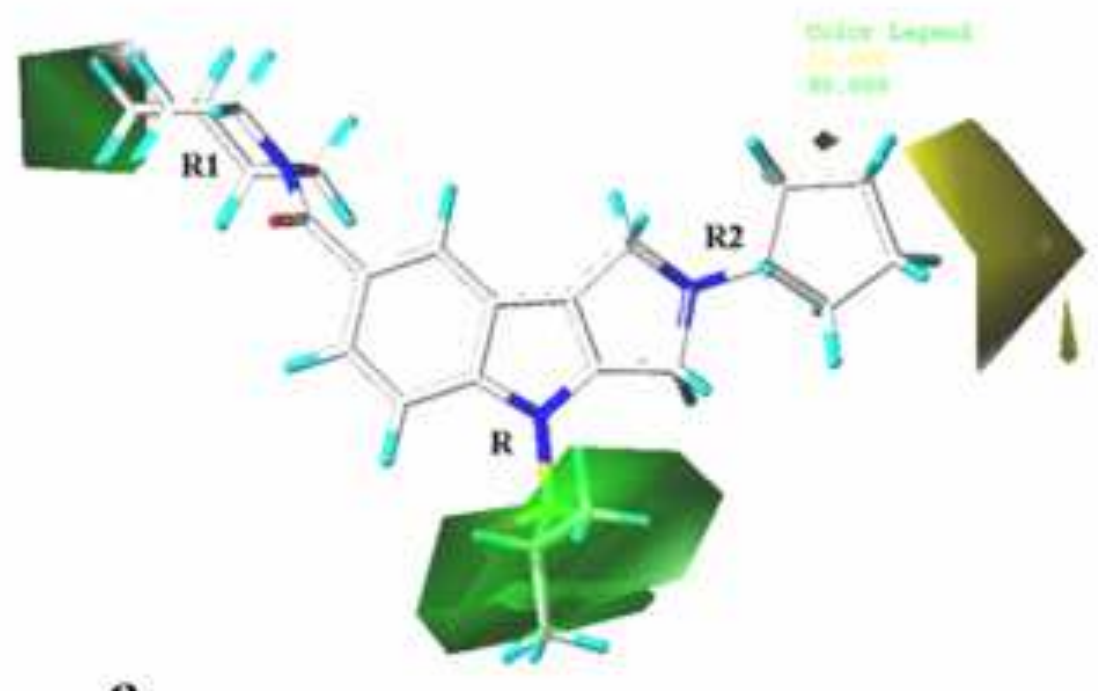

a

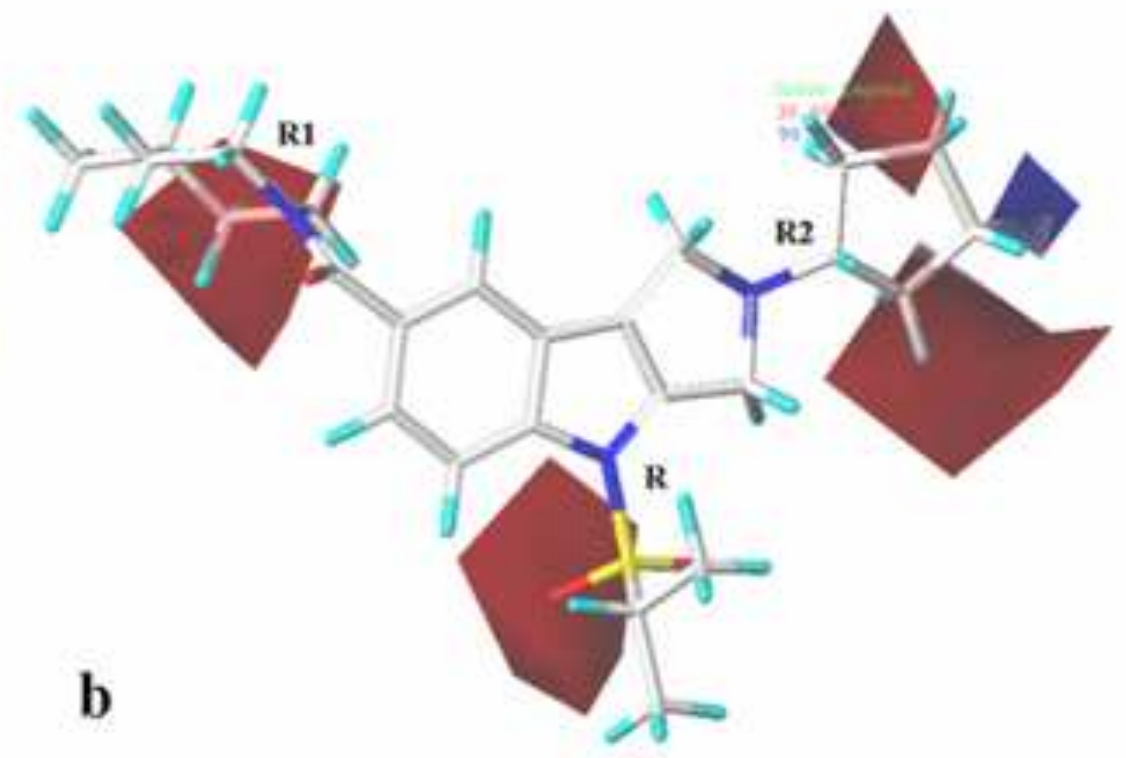




\section{Figure 3}

Click here to download high resolution image

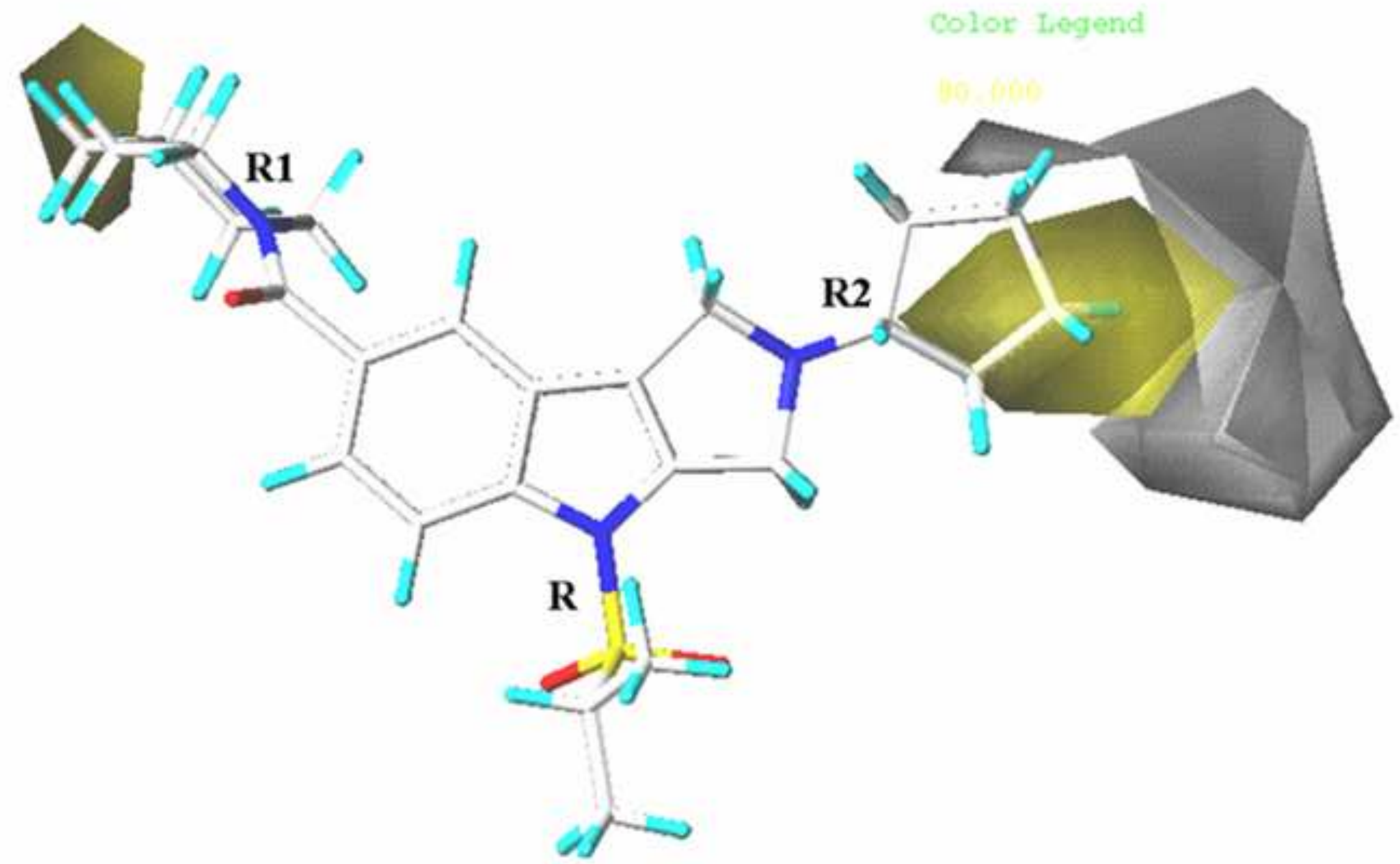




\section{Figure 4}

Click here to download high resolution image
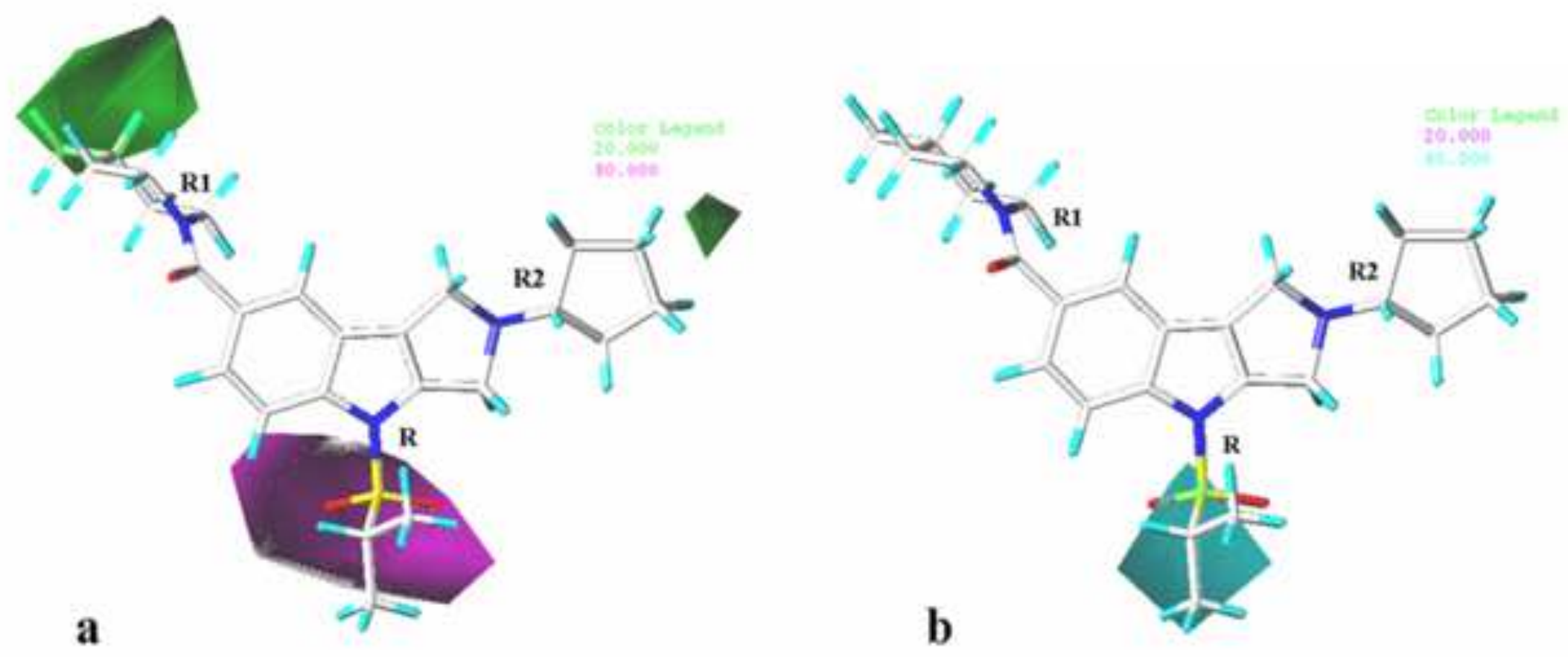


\section{Figure 5}

Click here to download high resolution image
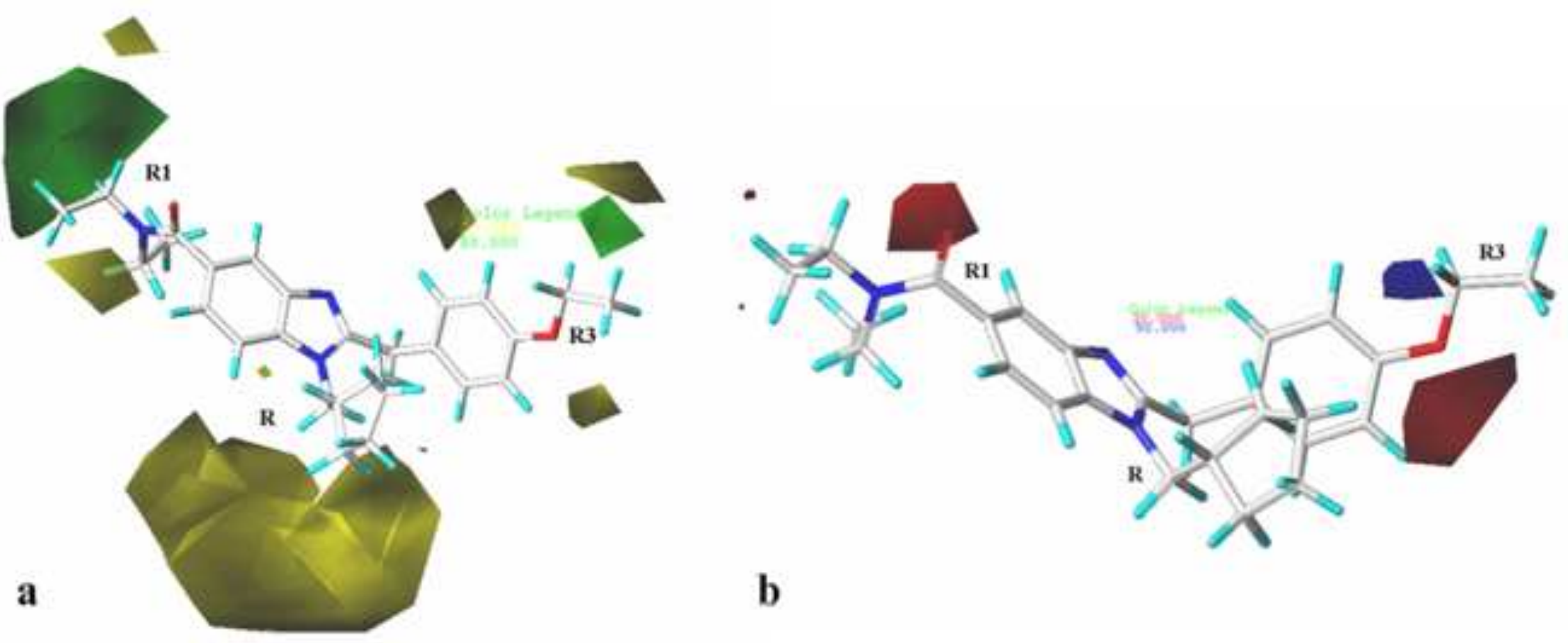

b 


\section{Figure 6}

Click here to download high resolution image

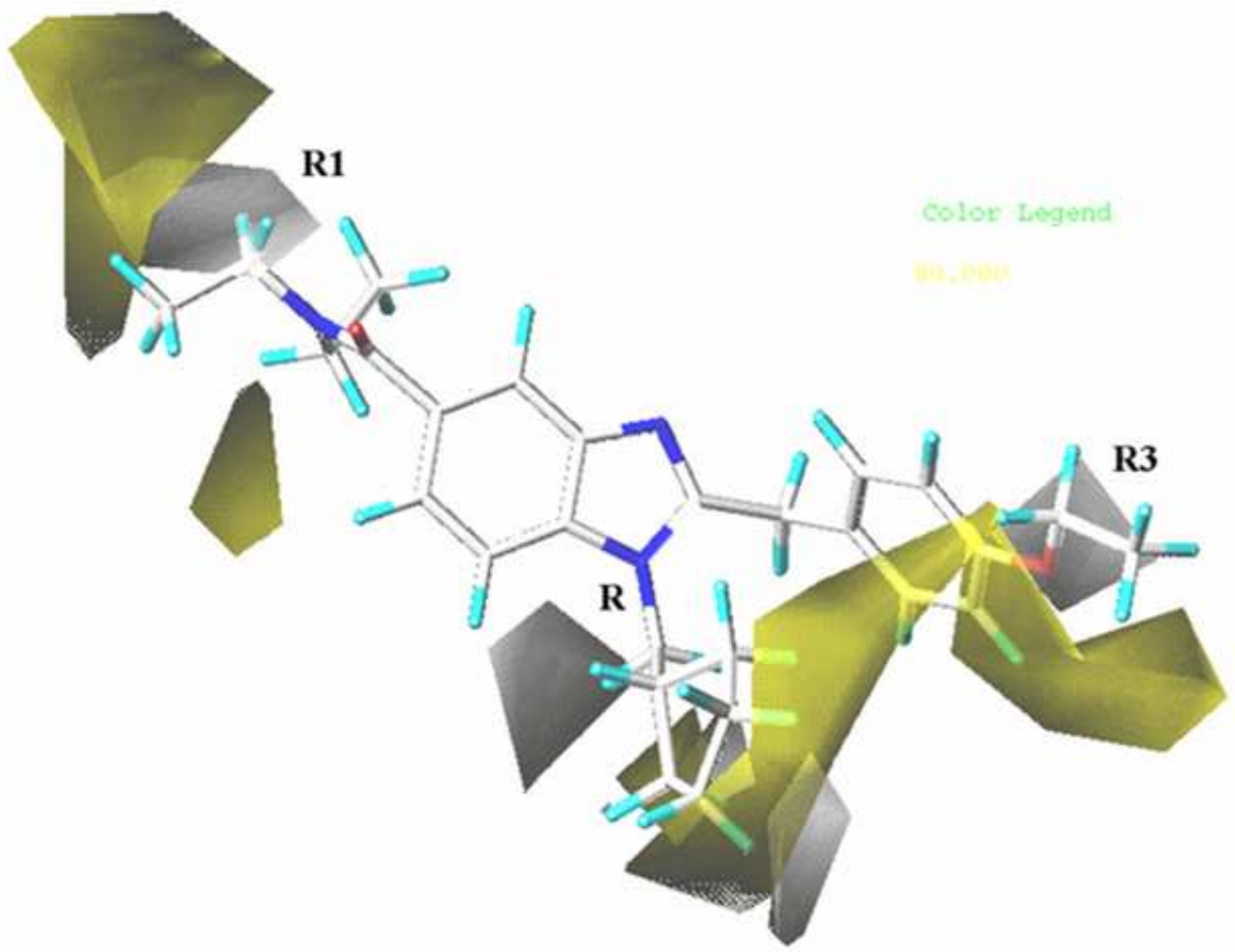



Click here to download high resolution image

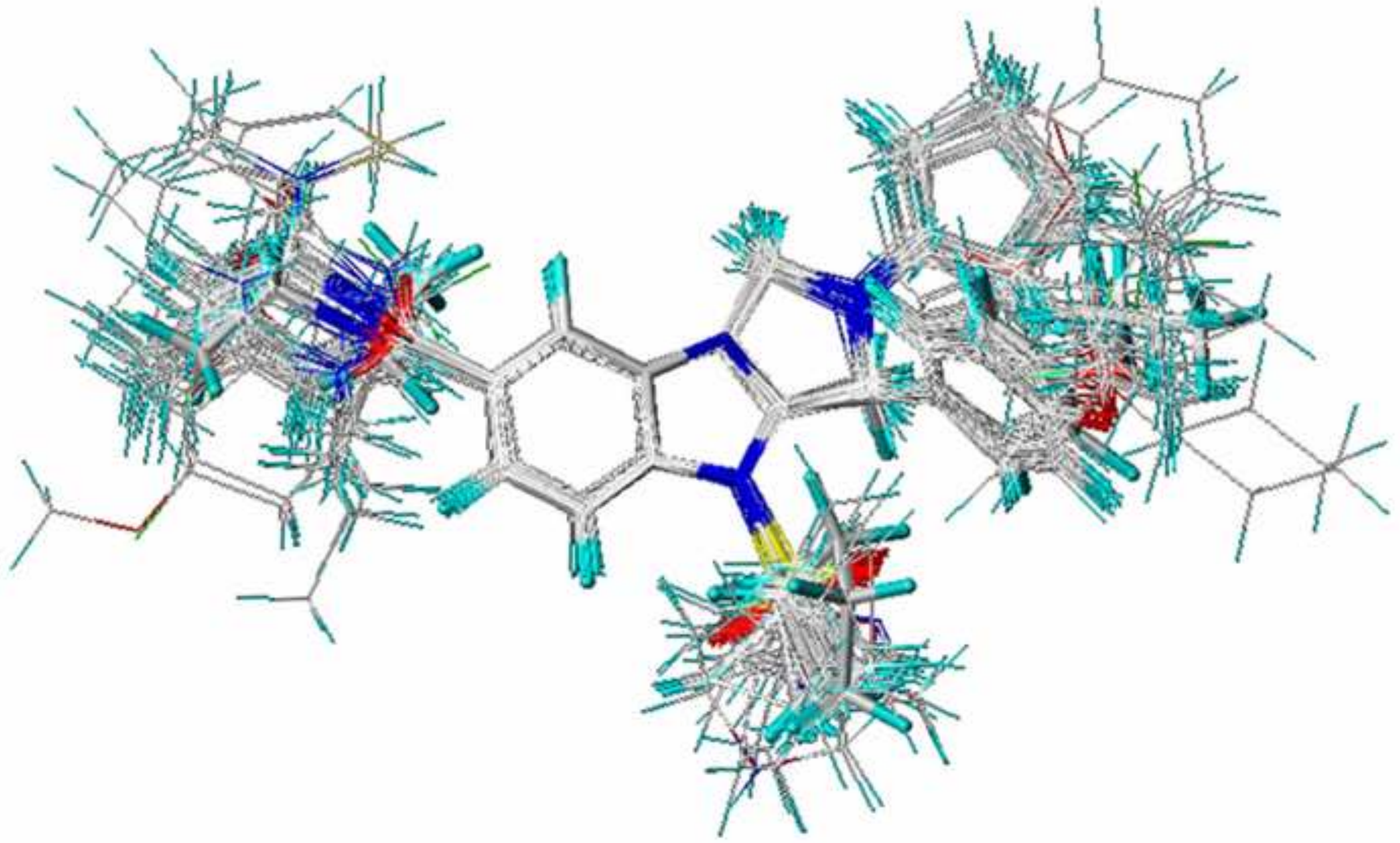


Click here to download high resolution image

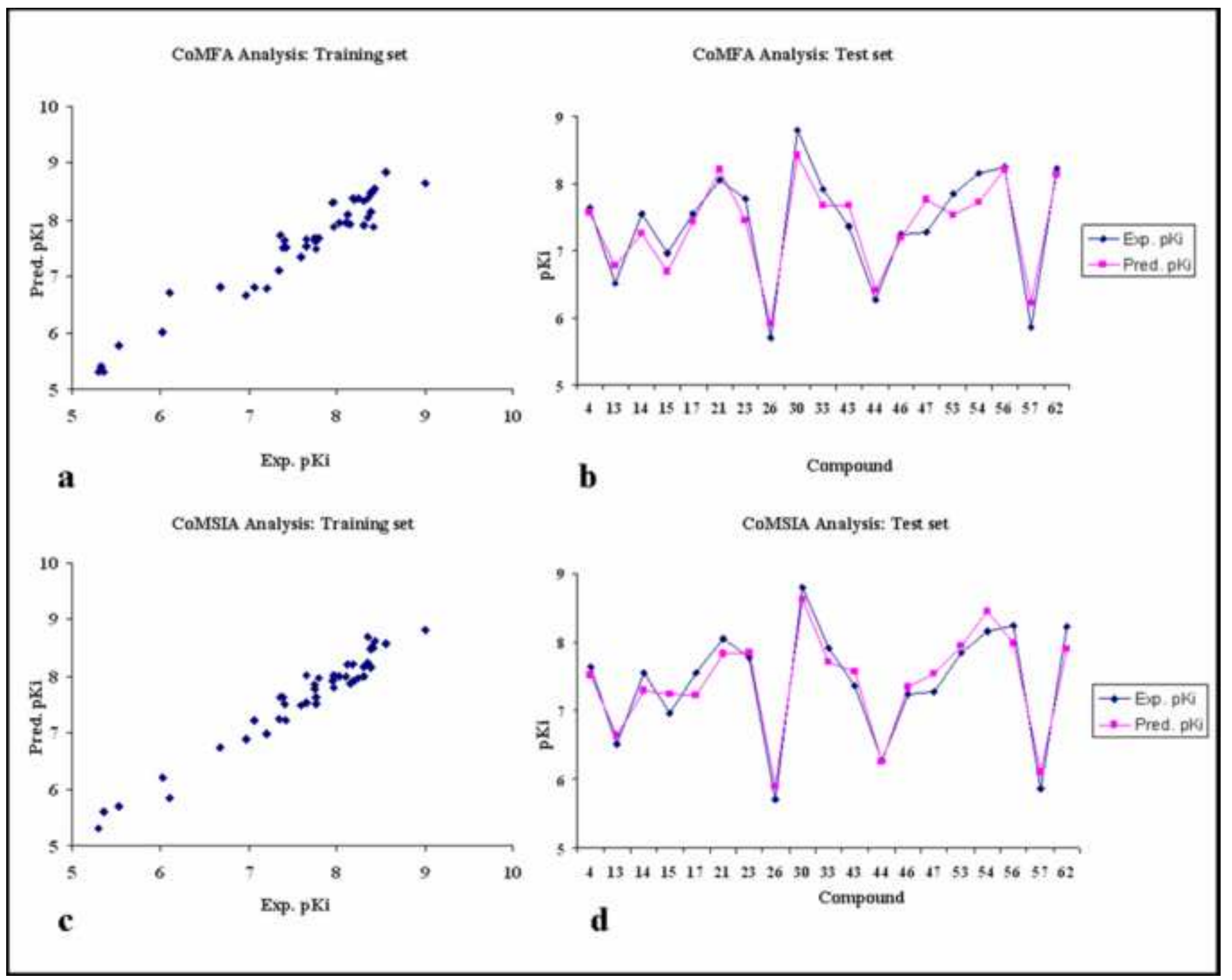




\section{Figure 1}

Click here to download high resolution image

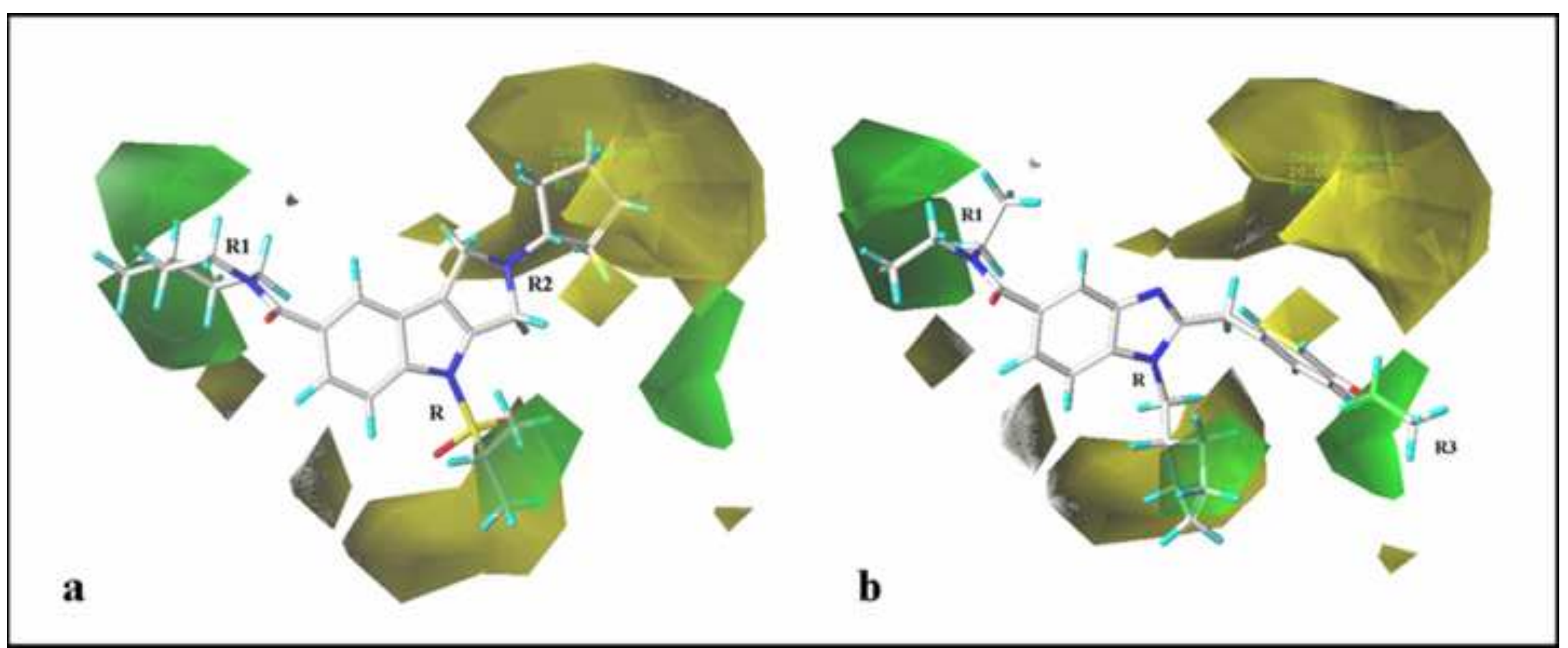




\section{Figure 11}

Click here to download high resolution image

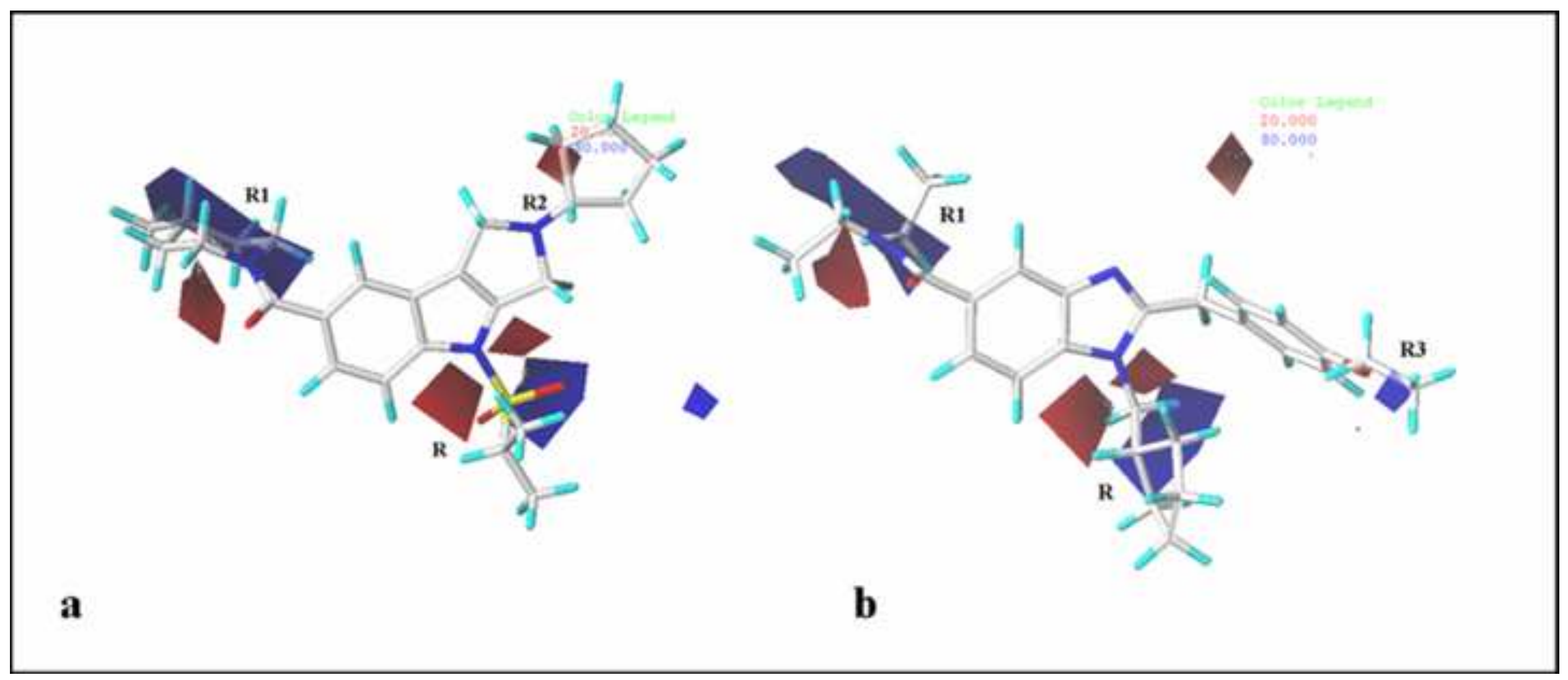




\section{Figure 12}

Click here to download high resolution image

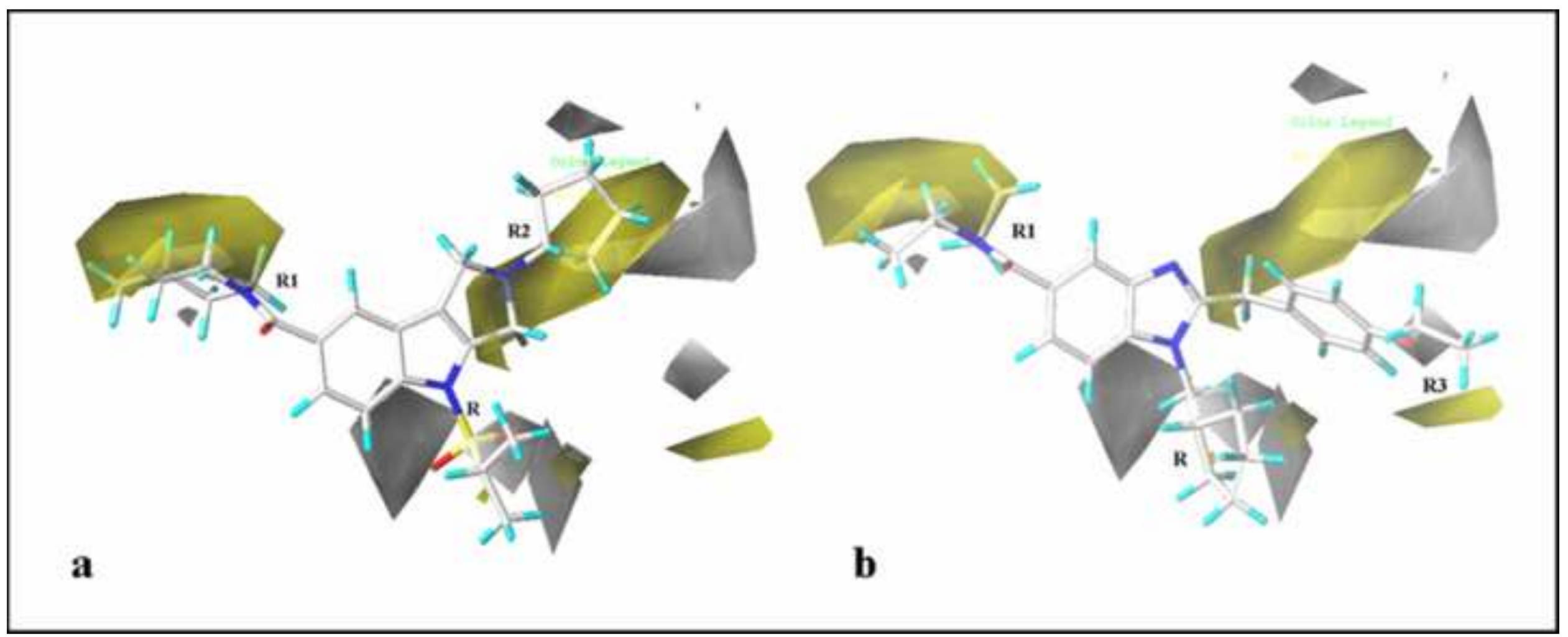




\section{Figure 13}

Click here to download high resolution image

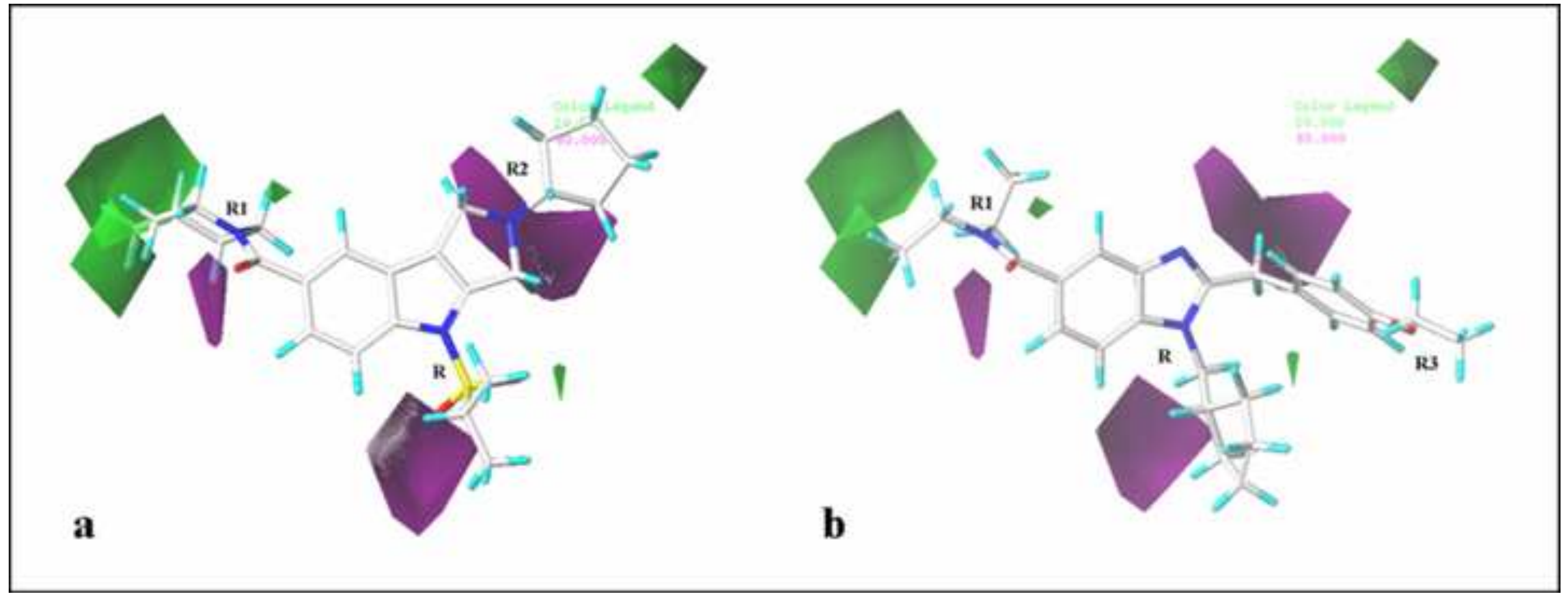


Click here to download high resolution image

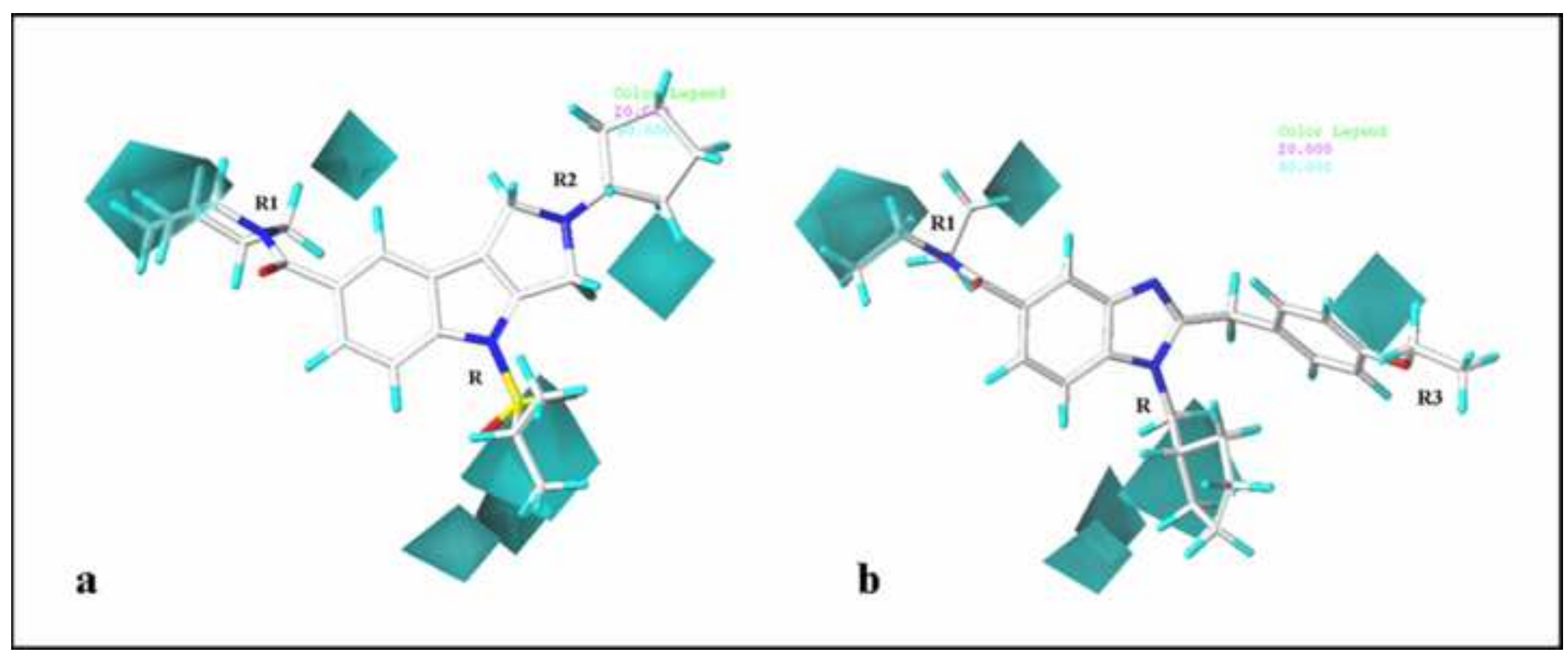

Click here to download high resolution image 


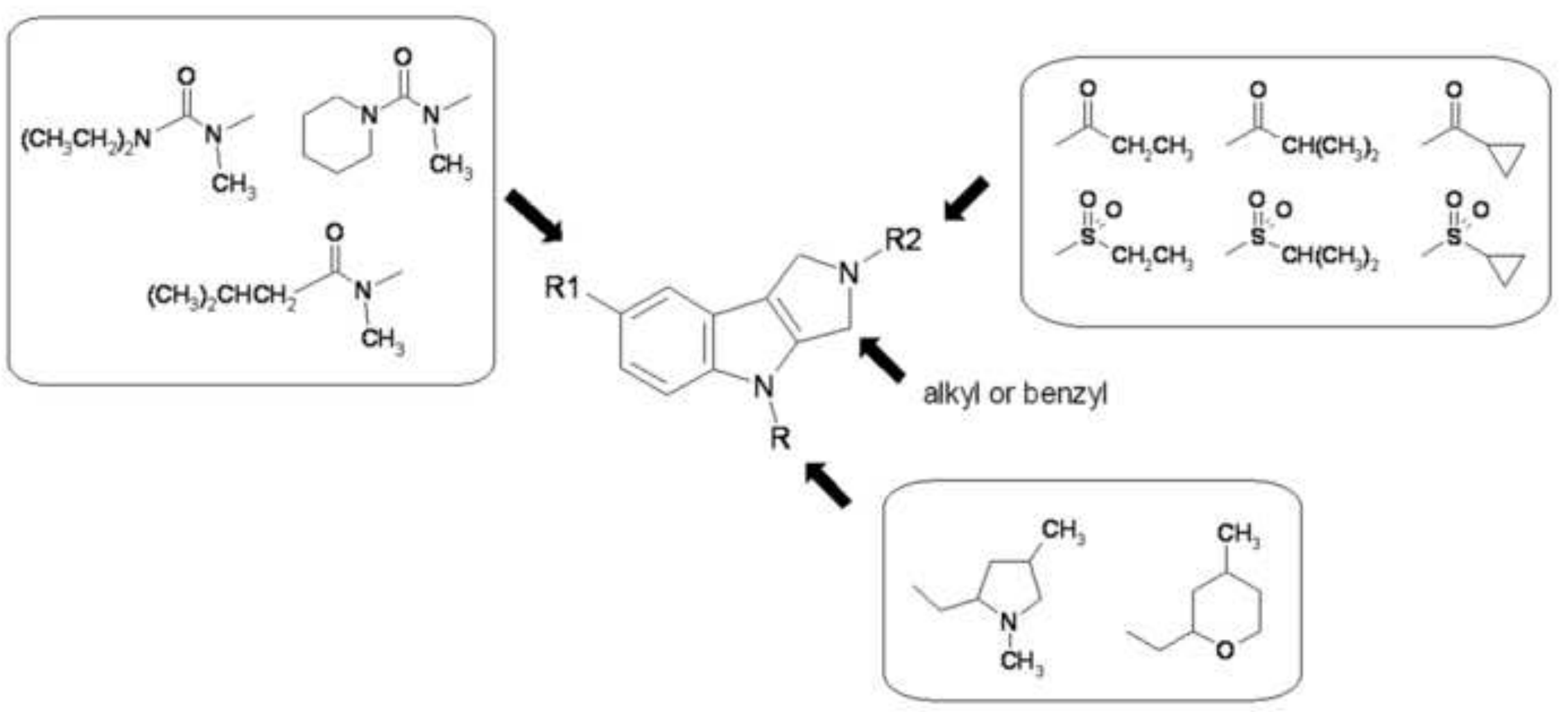


Click here to download high resolution image

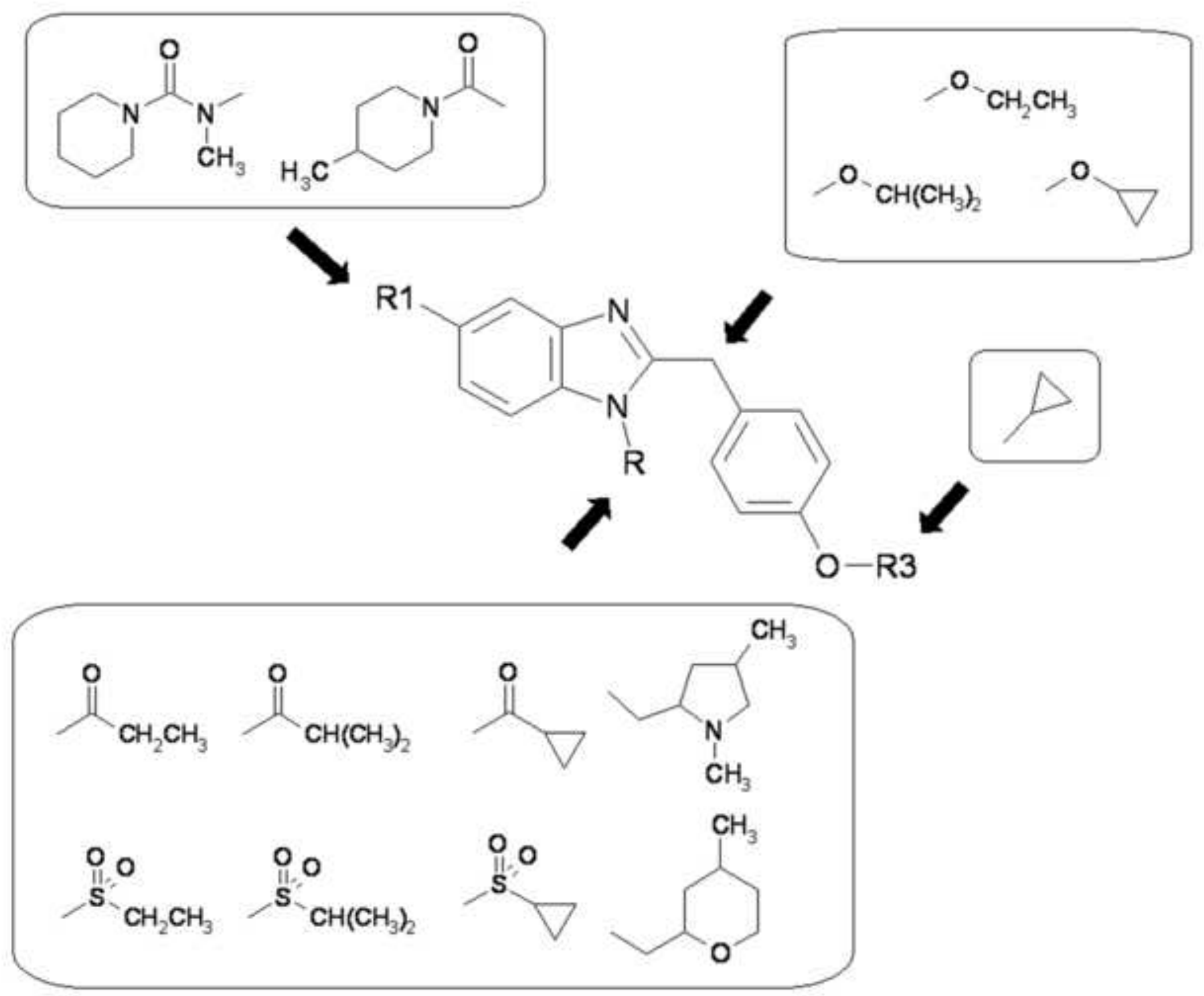

